\title{
Impact of Mesoscale Motions on Monin-Obukhov Similarity and Surface Energy Balance over a Homogeneous Surface
}

\author{
Yang Guo and Hongchao Zuo \\ College of Atmospheric Sciences, Lanzhou University, Lanzhou, China \\ Correspondence should be addressed to Hongchao Zuo; zuohch@lzu.edu.cn
}

Received 3 July 2017; Revised 19 October 2017; Accepted 9 November 2017; Published 28 November 2017

Academic Editor: Panuganti C. S. Devara

Copyright ( 2017 Yang Guo and Hongchao Zuo. This is an open access article distributed under the Creative Commons Attribution License, which permits unrestricted use, distribution, and reproduction in any medium, provided the original work is properly cited.

\begin{abstract}
Mesoscale motions are an important factor influencing the applicability of Monin-Obukhov similar theory (MOST) and the surface energy balance. The heterogeneous surface and the vegetation-covered surface also increase the complexity of these two problems. In order to understand the effect of mesoscale motions on turbulent fluxes more clearly, this study analyzes the impact of mesoscale motions on MOST and surface energy balance using the multiresolution decomposition method and the observational data over a homogeneous bare soil surface. Two conclusions are obtained: (1) When mesoscale motions are excluded, the scatter of similarity relations is evidently reduced; the observed values of the dimensionless velocity gradient and dimensionless temperature gradient in stable conditions become less than the values estimated using the universal functions, and the flux-variance relationship for temperature clearly deviates from the $-1 / 3$ power law. (2) When mesoscale motions are excluded, the number of energy balance closure outliers at night is dramatically reduced, and the energy balance ratio (EBR) is increased. However, when turbulent mixing is weak, even if mesoscale motions are excluded, the EBR is still relatively low, which is possibly due to the fact that the energy is mainly transported by mesoscale motions instead of turbulence.
\end{abstract}

\section{Introduction}

Turbulence is an important atmospheric movement in the boundary layer, and the exchange of energy and matter between surface and atmosphere is mainly conducted by turbulent transport. The Monin-Obukhov similarity theory (MOST) $[1,2]$ is the most fundamental theory in the study of atmospheric turbulence and has been adopted for landsurface processes in the current numerical models. However, the application of MOST in the stable boundary layer or on the heterogeneous surface is often limited [3-5]. With the advance of observational research, the energy balance closure problem [6-9], noticed in the 1980s, further complicated the application of MOST. Foken [2] pointed out that if the energy balance closure problem is caused by underestimation of the turbulent fluxes, the accuracy of the universal functions of MOST will be affected. At present, the applicability of MOST and the surface energy balance closure have become two significant problems restricting the development of boundary layer and land-surface process. Observations of boundary layer and land-surface processes suggest that land-surface characteristics and mesoscale motions are two important factors influencing the surface energy balance closure and the applicability of MOST.

The effects of land-surface characteristics on MOST and surface energy balance are mainly focused on vegetationcovered surface and horizontally heterogeneous surface. The roughness sublayer formed by vegetation canopy and the nonturbulent motions caused by heterogeneous surface limit the application of MOST $[2,5]$. Both the heat storage in the canopy [7] and the vertical advection transport on the heterogeneous surface [10] are difficult to measure, which reduces the energy balance closure. However, what should be noted is that the applicability of MOST and the energy balance closure problem are still not solved perfectly even on the flat surface. Observational studies show that the validity of MOST is often limited in the stable boundary layer [3, 11]. Wilson et al. [6] analyzed the surface energy balance of 22 FluxNet sites, and the results show that the surface energy imbalance is also prevalent on the flat surface.

Attention has also been paid to the impact of mesoscale motions on turbulent flux and MOST. Mahrt referred 
TABLE 1: Relevant studies on impact of mesoscale motions on similarity theory.

\begin{tabular}{|c|c|c|c|c|c|}
\hline Study & Position & Landscape & Stability & $\begin{array}{l}\text { Similarity } \\
\text { relation }\end{array}$ & Variable \\
\hline \multirow{4}{*}{ Mahrt (2007) } & Colorado, USA & Grassland & \multirow{4}{*}{ Stable } & \multirow{4}{*}{$(1)$} & \multirow{4}{*}{ Wind } \\
\hline & Kansas, USA & Shore & & & \\
\hline & Massachusetts, USA & Short tundra & & & \\
\hline & Alaska, USA & & & & \\
\hline \multirow{2}{*}{ Sorbjan and Grachev (2010) } & Alaska, USA & Arctic pack ice & \multirow{2}{*}{ Stable } & \multirow{2}{*}{$(1)$} & \multirow{2}{*}{$\begin{array}{l}\text { Wind and } \\
\text { temperature }\end{array}$} \\
\hline & Kansas, USA & Grassland & & & \\
\hline Liang et al. (2014) & Lanzhou, China & Loess Plateau & Stable & (1) & Wind \\
\hline Babić (2016) & Kutina, Croatia & $\begin{array}{c}\text { Walnut trees } \\
\text { Heterogeneous surface }\end{array}$ & Stable & (1) and (2) & Wind \\
\hline This study & $\begin{array}{c}\text { Alxa, Inner Mongolia, } \\
\text { China }\end{array}$ & $\begin{array}{c}\text { Homogeneous bare soil } \\
\text { surface }\end{array}$ & $\begin{array}{l}\text { Stable and } \\
\text { unstable }\end{array}$ & (1) and (2) & $\begin{array}{l}\text { Wind and } \\
\text { temperature }\end{array}$ \\
\hline
\end{tabular}

Note. (1): flux-gradient relationship; (2): flux-variance relationship.

to some nonturbulent motions in the boundary layer as "mesoscale motions" and carried out a series of studies [1214]. Mesoscale motions can include internal gravity waves, drainage flows, density currents, solitons, and numerous motions more difficult to categorize [12, 15]. Mesoscale motions are nonstationary and independent of the gradient transport in the vertical direction, having larger time scale than turbulence. When the turbulent fluxes observed in the boundary layer are contaminated by mesoscale motions, the turbulent fluxes often deviate greatly from the estimated values of mean flows [16], and the statistical characteristics of the turbulence also show various forms [4, 12]. Vickers and Mahrt [15] developed the multiresolution decomposition (MRD) method to exclude the mesoscale motions involved in the turbulent fluxes based on the fact that mesoscale motions have larger timescale than turbulence. With the help of the MRD method, the influence of mesoscale motions on MOST has been widely analyzed (Table 1) $[4,12,17,18]$, and the results show that excluding mesoscale motions can reduce the scatter in the similarity relations in stable conditions. Meanwhile, the turbulent fluxes can also be affected by mesoscale motions. Vickers and Mahrt [19] pointed out that the removal of mesoscale motions can result in more coherent turbulent fluxes in the vertical direction. Mahrt [16] emphasized that poorly sampled mesoscale fluxes can severely contaminate the computation of turbulent fluxes. Since turbulent fluxes are important components of surface energy balance, the errors existing in turbulent fluxes will further affect the surface energy balance.

The energy balance closure problem, horizontally heterogeneous surface, mesoscale motions, and uncertainty in the turbulence observation are intertwined in the current research of boundary layer and land-surface process, which complicates the research. When studying the effect of mesoscale motions on turbulence characteristics, the heterogeneous surface makes the problem more complex. However, most of the previous relevant studies are conducted on heterogeneous or vegetation-covered surfaces (Table 1). When the effect of a heterogeneous surface is excluded, how does mesoscale motion impact the similarity theory? Can the energy balance closure be improved after mesoscale motions are excluded? These questions remain to be resolved. Therefore, we carried out a field experiment over a horizontally homogeneous, bare soil surface in an arid area. By eliminating the effects of heterogeneous surface and vegetation-covered surface, this paper attempts to more clearly determine the impact of mesoscale motions on MOST and the surface energy balance closure. The remainder of this paper is divided into three sections. The site, data, and analysis methods are described in Section 2. The impact of mesoscale motions on MOST and the surface energy balance is presented in Section 3, followed by conclusions and discussions in Section 4.

\section{Data and Methods}

2.1. Site Description and Instrumentation. The experimental site $\left(37^{\circ} 45^{\prime} \mathrm{N}, 103^{\circ} 55^{\prime} \mathrm{E}\right.$; a.s.l: $\left.1563 \mathrm{~m}\right)$ is located at the southern border of Tengger Desert, in Alxa Left Banner, Inner Mongolia. This area features a typical northern arid temperate climate. The topography of the experimental site is shown in Figure 1. The surface is essentially homogeneous bare soil, despite the scattered perennial Alhagi sparsifolia and sparse low weeds. From 1971 to 2000, the region had a mean annual precipitation of $35.2 \mathrm{~mm}$ mainly in May-September, mean annual potential evaporation of $3400 \mathrm{~mm}$, mean annual relative humidity of $33 \%$, and mean annual wind speed of $3.2 \mathrm{~m} / \mathrm{s}$ at $10 \mathrm{~m}$ elevation. The mean monthly air temperatures range from $-10.5^{\circ} \mathrm{C}$ in December to $27.6^{\circ} \mathrm{C}$ in July [20]. The local time at the experimental site is 1 hour and 4 minutes later than Beijing Time (UTC $+8 \mathrm{~h}$ ), and Beijing Time is used in this research.

One 32-m-high meteorological tower was set up in the experimental field. There were 6-level wind speed sensors (010C, Met One) at $1 \mathrm{~m}, 2 \mathrm{~m}, 4 \mathrm{~m}, 8 \mathrm{~m}, 16 \mathrm{~m}$, and $32 \mathrm{~m}$; 6level air temperature and relative humidity sensors (HC2S3, Campbell) at these 6 heights; and a wind direction sensor (W200P, Vector) at $10 \mathrm{~m}$. An eddy-covariance (EC) system 


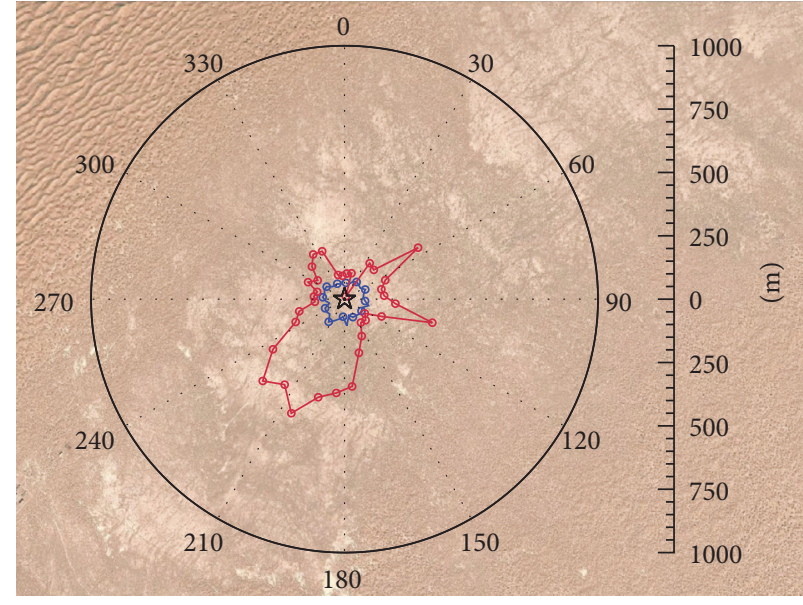

$\leftrightarrow \leftrightarrow \zeta \leq 0$

(a)

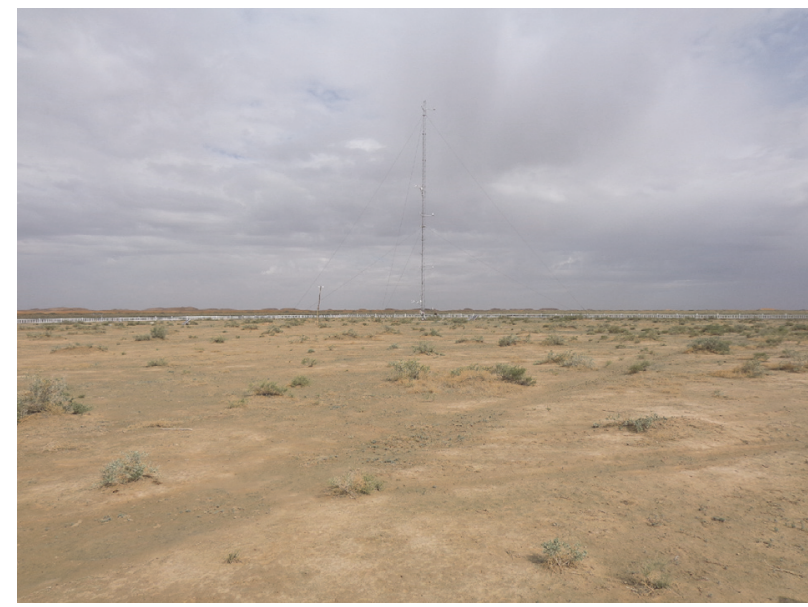

$$
\leftrightarrow \zeta>0
$$

(b)

FIGURE 1: Topography of the experimental site and footprint of the turbulent fluxes. The center of the circle is the position of meteorological tower. The red and blue solid lines are the mean distances providing $50 \%$ contribution to turbulent fluxes in stable and unstable conditions, respectively.

was installed at $3 \mathrm{~m}$ for turbulence observations, including a 3-D sonic anemometer (CAST3, Campbell) and an open-path infrared gas analyzer (Li-7500, Campbell). South of the tower, a 4-component net radiation sensor (CNR4, Kipp \& Zonen) was installed at a height of $1.5 \mathrm{~m}$ for radiation observations. The soil temperature sensors (STP01, Hukseflux) and soil moisture sensors (CS616, Campbell) were buried at depths of $5 \mathrm{~cm}, 10 \mathrm{~cm}, 20 \mathrm{~cm}, 40 \mathrm{~cm}$, and $80 \mathrm{~cm}$, and the soil heat flux plates (HFP01SC, Hukseflux) were buried at depths of $5 \mathrm{~cm}, 10 \mathrm{~cm}$, and $20 \mathrm{~cm}$. All these sensors were set about $10 \mathrm{~m}$ far from south of the tower. The sampling frequency of the EC system was $10 \mathrm{~Hz}$, while other data were stored as $10 \mathrm{~min}$ averages from 1 s samples.

We selected 90-day observation data obtained from December 1, 2014, to February 28, 2015, for study. To guarantee the quality of turbulence data, several postfield data processing methods were applied to the turbulence data using the postprocessing software Edire [26]. These data processing methods are as follows: spike removal [27], coordinate rotation [28], time delay between different sensors, sonic temperature correction [29], frequency response correction [30], and WPL correction [31]. In order to ensure that the observed turbulent fluxes are mainly contributed by the bare soil surface, the footprint of the turbulent fluxes was analyzed (Figure 1(a)) [32, 33]. The border of Tengger Desert is about $1 \mathrm{~km}$ northwest of the experimental site, so the area within $1 \mathrm{~km}$ range of the meteorological tower was selected as the target area. If the flux contribution is less than $50 \%$ in the target area, the data are a set of disorders, which is not recommended for research [34]. Accordingly, the data with flux contribution less than 50\% were removed. Figure 1(a) shows that the mean distances providing 50\% contribution to turbulent fluxes are far less than $1 \mathrm{~km}$ both in stable and unstable conditions for the remaining data, which indicates that the turbulent fluxes can well represent the contribution of the bare soil surface.

2.2. Analysis Method. When turbulent fluxes are measured by an EC system, one needs to select a reasonable averaging time, $\tau$, to define the turbulent fluctuations. The length of $\tau$ is critical, as it determines whether turbulent fluxes will be affected by mesoscale motions $[15,19]$. If $\tau$ is too short, the contribution of large-scale eddies will not be integrally captured by the EC system, and the calculated turbulent flux will be too small; if $\tau$ is too long, the calculated turbulent flux will be contaminated by mesoscale motions and show intense oscillation, and even its direction will be opposite to the true one. Figure 2(a) shows the ogive functions [35] of $\overline{w^{\prime} T^{\prime}}$ (covariance of vertical velocity fluctuation $w^{\prime}$ and temperature fluctuation $T^{\prime}$ ) hour by hour, which is calculated using the data from December 1-3, 2014, at 20:00-07:00. As seen in Figure 1(a), if $\tau$ is set to the conventional value of $30 \mathrm{~min}$, the ogive functions of $\overline{w^{\prime} T^{\prime}}$ show intense oscillation at certain hours, which reflects the impact of the mesoscale motions on the calculated turbulent fluxes.

To minimize the impact of mesoscale motions on turbulent fluxes, the multiresolution decomposition (MRD) method [15] was used to determine a reasonable averaging time. This method decomposes the flux into different time scales, and an MRD cospectrum can be obtained. There is usually a clear cospectral gap in the MRD cospectrum that separates the turbulence and mesoscale motions (Figure 2(b)). Mesoscale motions can be excluded if the timescale associated with the cospectral gap $\left(\tau_{\text {gap }}\right)$ is used as the averaging time for defining turbulent fluctuations. In this study, MRD analysis was performed on the hourly highfrequency turbulence data. Vickers and Mahrt [19] pointed 


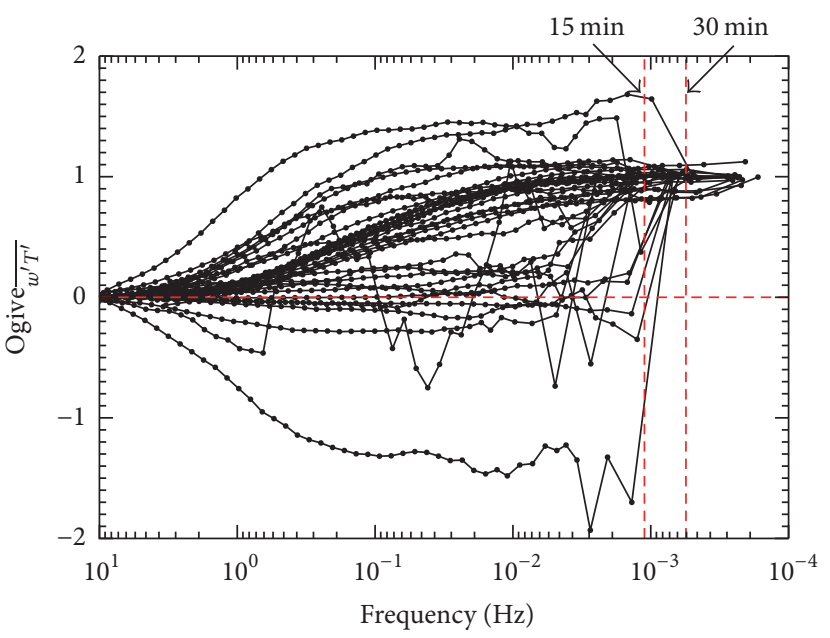

(a)

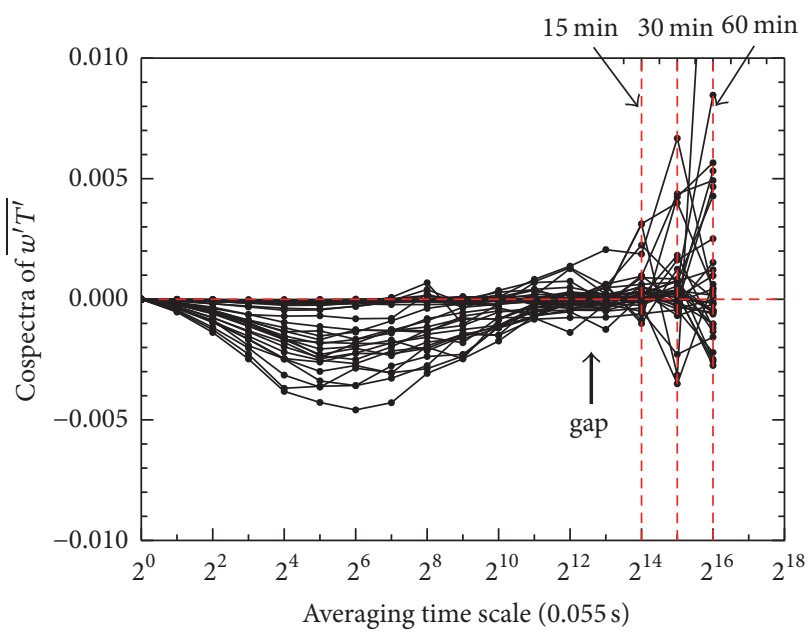

(b)

FIGURE 2: Influence of averaging time $\tau$ on turbulence covariance $\overline{w^{\prime} T^{\prime}}$. (a) Ogive functions of $\overline{w^{\prime} T^{\prime}}$. (b) Corresponding MRD cospectra of $\overline{w^{\prime} T^{\prime}}$.

TABLE 2: Universal functions of flux-gradient relationship proposed by different authors [21-25].

\begin{tabular}{lcccc}
\hline Author & \multicolumn{1}{c}{$\varphi_{m}$} & Unstable & Stable & $\varphi_{h}$ \\
& $\varphi_{m}=(1-15 \zeta)^{-1 / 4}$ & $\varphi_{m}=1+4.7 \zeta$ & $\varphi_{h}=0.74(1-9 \zeta)^{-1 / 2}$ & Stable \\
\hline Businger et al. (1971) & $\varphi_{m}=(1-16 \zeta)^{-1 / 4}$ & $\varphi_{m}=1+5 \zeta$ & $\varphi_{h}=(1-16 \zeta)^{-1 / 2}$ & $\varphi_{h}=0.74+4.7 \zeta$ \\
Dyer (1974) & $\varphi_{m}=(1-22 \zeta)^{-1 / 4}$ & $\varphi_{m}=1+6.9 \zeta$ & $\varphi_{h}=(1-13 \zeta)^{-1 / 2}$ & $\varphi_{h}=1+5 \zeta$ \\
Wieringa (1980) & $\varphi_{m}=(1-19.3 \zeta)^{-1 / 4}$ & $\varphi_{m}=1+4.8 \zeta$ & $\varphi_{h}=(1-12 \zeta)^{-1 / 2}$ & $\varphi_{h}=1+9.2 \zeta$ \\
Högström (1988) & $\varphi_{m}=(1-19.3 \zeta)^{-1 / 4}$ & $\varphi_{m}=1+6 \zeta$ & $\varphi_{h}=0.95(1-11.6 \zeta)^{-1 / 2}$ & $\varphi_{h}=1+7.8 \zeta$ \\
Foken (2008) & & $\varphi_{h}=0.95+7.8 \zeta$ \\
\hline
\end{tabular}

Note. $\varphi_{m}$ is the dimensionless velocity gradient, $\varphi_{h}$ is the dimensionless temperature gradient, and $\zeta$ is the atmospheric stability.

out that the MRD cospectral gaps based on heat flux and momentum flux are highly correlated and the heat flux cospectra behave typically better. For ease of processing, $\tau_{\text {gap }}$ values were determined by the heat flux cospectra. In order to prevent the horizontal velocity component from interfering with the vertical velocity component, a coordinate rotation correction [28] was conducted first, after which the MRD cospectra were calculated and $\tau_{\text {gap }}$ values were determined.

To understand the effect of mesoscale motions on application of MOST, the flux-gradient and flux-variance relationships were studied by comparing these relationships when the mesoscale motions are excluded with those when the mesoscale motions are not excluded. As to the flux-gradient relationship, five widely used universal functions [21-25] (Table 2) were employed to evaluate the impact of mesoscale motions on MOST. As to the flux-variance relationship, the empirical function proposed by Panofsky et al. [36] was used to fit the flux-variance relationship for wind speed:

$$
\frac{\sigma_{w}}{u_{*}}=\alpha(1+\beta \zeta)^{1 / 3}
$$

where $\sigma_{w}$ is the standard deviation of vertical velocity, $u_{*}$ is the friction velocity, $\zeta$ is the atmospheric stability (where $\zeta=$ $z$ / $L$ with $z$ as height and $L$ as the Obukhov length), and $\alpha$ and $\beta$ are the fit coefficients. As to the flux-variance relationship for temperature, it is generally assumed that the relationship between the normalized standard deviation of temperature $\left(\sigma_{T} / T_{*}\right)$ and atmospheric stability $(\zeta)$ follows the $-1 / 3$ power law $[37,38]$ :

$$
\frac{\sigma_{T}}{T_{*}}=C(-\zeta)^{-1 / 3}
$$

where $\sigma_{T}$ is the standard deviation of temperature fluctuation, $T_{*}$ is the characteristic temperature, and $C$ is a fit coefficient. With respect to humidity, because of the weak water vapor exchange in arid areas, there is great uncertainty in the humidity gradient; thus we do not conduct an analysis of humidity in this research.

The equation for surface energy balance over a homogeneous bare soil surface can be expressed as

$$
R_{n}-G_{0}=H+\lambda E,
$$

where $R_{n}$ is the net radiation, $G_{0}$ is the surface soil heat flux, $H$ is the sensible heat flux, $\lambda E$ is the latent heat flux, $R_{n}-G_{0}$ is called the available energy, and $H+\lambda E$ is called the turbulent flux. The surface energy balance closure is evaluated using the EBR (energy balance ratio) method [6]. EBR is defined as

$$
\mathrm{EBR}=\frac{\sum(H+\lambda E)}{\sum\left(R_{n}-G_{0}\right)} .
$$


EBR reflects the long-term surface energy balance. The hourly energy balance ratio is defined as

$$
\mathrm{EBR}_{h}=\frac{H+\lambda E}{R_{n}-G_{0}},
$$

where $H+\lambda E$ is the hourly turbulent flux and $R_{n}-G_{0}$ is the hourly available energy.

2.3. Experimental Design. In order to understand the impact of mesoscale motions on MOST and the surface energy balance, three methods (experiments) were designed to exclude mesoscale motions, and their results were compared.

EMT 1: $\tau=30 \mathrm{~min}$, with records of $\tau_{\text {gap }}<1 \mathrm{~min}$ unremoved.

EMT 2: $\tau=30 \mathrm{~min}$, with records of $\tau_{\text {gap }}<1 \mathrm{~min}$ removed.

EMT 3: $\tau=\tau_{\text {gap }}$, with records of $\tau_{\text {gap }}<1 \mathrm{~min}$ removed.

For ease of comparison, the hourly averaged fluxes were calculated in each experiment. In the three experiments, there were some records where $\tau_{\text {gap }}$ were less than $1 \mathrm{~min}$, and the turbulent fluxes of these records were not calculated directly using $\tau=\tau_{\text {gap }}$. One reason is that the minimum optional timescale to implement the data processing and flux calculation in the Edire software is $1 \mathrm{~min}$; another reason is that if very few data are used to calculate turbulent fluxes, there may be great errors in the data processing and flux calculation. Therefore, the effect of mesoscale motions on turbulent fluxes in records where $\tau_{\text {gap }}<1 \mathrm{~min}$ was analyzed by comparing EMT 1 with EMT 2 . In order to completely remove the mesoscale motions, the turbulent fluxes were further calculated using $\tau=\tau_{\text {gap }}$ in EMT 3 on the basis of EMT 2. It should be noted that when $\tau_{\text {gap }}$ is determined by MRD method, the MRD method can determine the cospectral values only at $2^{n} \Delta t$ ( $n$ is an integer, $\Delta t=0.055 \mathrm{~s}$ ). For the convenience of calculating hourly averaged fluxes, we, respectively, adopted $\tau=1 \mathrm{~min}, 2 \mathrm{~min}, 4 \mathrm{~min}, 10 \mathrm{~min}$, $15 \mathrm{~min}, 30 \mathrm{~min}$, or $60 \mathrm{~min}$ (approximately corresponding to $\tau_{\text {gap }}=2^{10} \Delta t, 2^{11} \Delta t, 2^{12} \Delta t, 2^{13} \Delta t, 2^{14} \Delta t, 2^{15} \Delta t$, and $\left.2^{16} \Delta t\right)$ to calculate turbulent fluxes in EMT 3; the hourly averaged turbulent fluxes were then calculated.

2.4. Data Selection. Because of frost, snow, and other severe weather conditions, 41 hours of low-quality data were removed. Furthermore, the hours near sunrise (8:00-10:00) and sunset (17:00-19:00) were also excluded, as atmospheric motion is usually unsteady at these times. The records whose MRD cospectrum had no obvious cospectral gap were excluded. In the analysis of MOST, the data with $u_{*}<$ $0.05 \mathrm{~m} / \mathrm{s}$ or $-0.05<T_{*}<0.05$ were excluded. In the analysis of surface energy balance closure, the data with $-10 \mathrm{~W} / \mathrm{m}^{2}<$ $R_{n}-G_{0}<10 \mathrm{~W} / \mathrm{m}^{2}$ were removed because the energy balance closure is inaccurate when $R_{n}-G_{0}$ (denominators of EBR and $\mathrm{EBR}_{h}$ ) is close to $0 \mathrm{~W} / \mathrm{m}^{2}$. Finally, 1030 and 1110 hours of data remain in the analysis of MOST and the surface energy balance, respectively.

\section{Results}

3.1. Impact of Mesoscale Motion on Similarity Theory. Mesoscale motions limit the application of MOST in complex meteorological conditions by affecting the flux-gradient and flux-variance relationships. The impact of mesoscale motions on the flux-gradient relationship for wind speed is analyzed first. Figure 3 shows the flux-gradient relationship before and after mesoscale motions are excluded, and five commonly used universal functions [21-25] are depicted. Figure 3 indicates that the dependence of the dimensionless velocity gradient $\left(\varphi_{m}\right)$ on atmospheric stability $(\zeta)$ can be well established whether or not mesoscale motions are excluded. However, there is a large scatter in the relationship between $\varphi_{m}$ and $\zeta$ before mesoscale motions are removed (Figure 3(a)), and the scatter is even larger in stable conditions. The scattered points mainly correspond to the records with $\tau_{\text {gap }}<1 \mathrm{~min}$, and there are 114 of these records, accounting for $11.1 \%$ of the analyzed samples. After the records with $\tau_{\text {gap }}<1 \mathrm{~min}$ are removed by the EMT 2 method (Figure 3(b)), the scatter between $\varphi_{m}$ and $\zeta$ is significantly reduced, especially in stable conditions. After mesoscale motions are thoroughly excluded by the EMT 3 method (Figure 3(c)), the relationship between $\varphi_{m}$ and $\zeta$ is further improved, but the observed values of $\varphi_{m}$ become smaller than the values estimated using the five universal functions in stable conditions. Through comparing the five universal functions with the observed results, the universal function proposed by Businger et al. [21] is found to be closest to the observed results after mesoscale motions are thoroughly excluded, so we quantify the difference between the universal function of Businger et al. and the observed results and list it in Table 3 . Table 3 indicates that, in unstable conditions, the exclusion of mesoscale motions by the EMT 3 method makes the observed values of $\varphi_{m}$ closer to the values estimated using the universal function of Businger et al. [21]. However, the result is opposite in stable conditions: the observed values of $\varphi_{m}$ become smaller than the values estimated by the universal function, and the larger the $\zeta$ is, the larger the deviations will be.

The flux-variance relationship for wind speed is shown in Figure 4. Whether atmospheric stratification is stable or unstable, the relationship between the normalized standard deviation of vertical velocity $\left(\sigma_{w} / u_{*}\right)$ and atmospheric stability $(\zeta)$ essentially follows the $1 / 3$ power law. Nevertheless, in EMT 1 (Figure 4(a)), there is a large scatter in the relationship between $\sigma_{w} / u_{*}$ and $\zeta$, and the root mean square errors (RMS) are 0.26 and 0.22 for the conditions where $\zeta<0$ and $\zeta>0$, respectively. After mesoscale motions are removed by the EMT 2 method (Figure 4(b)), there is an obvious decrease in the scatter between $\sigma_{w} / u_{*}$ and $\zeta$, and the RMS is reduced by 0.14 and 0.09 for conditions where $\zeta<0$ and $\zeta>0$, respectively. Moreover, after mesoscale motions are thoroughly excluded by the EMT 3 method (Figure 4(c)), the scatter between $\sigma_{w} / u_{*}$ and $\zeta$ is further decreased, and a more perfect relation results. The RMS is decreased by 0.03 when $\zeta>0$ but is increased by 0.06 when $\zeta<0$. The disappointing result where $\zeta<0$ is related to the large scatter in very unstable conditions. After mesoscale motions are excluded, the fit coefficients are also obviously changed: 


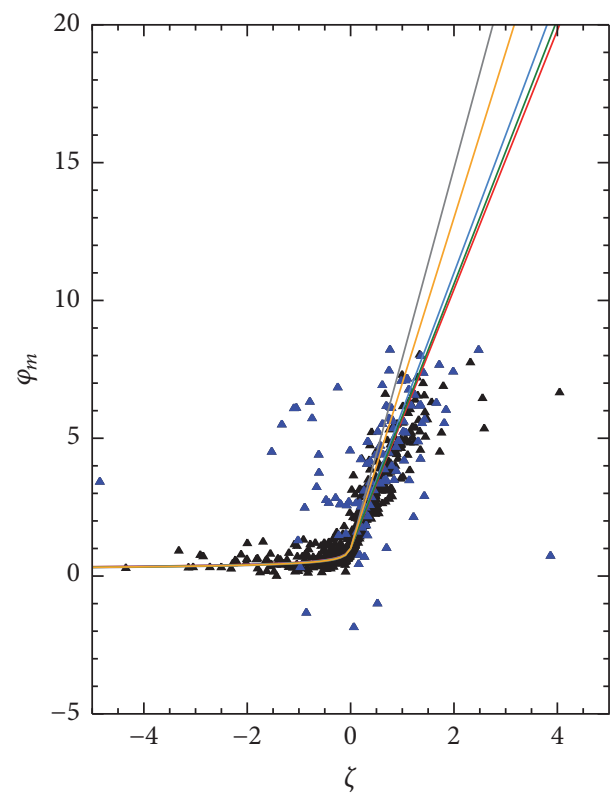

(a)

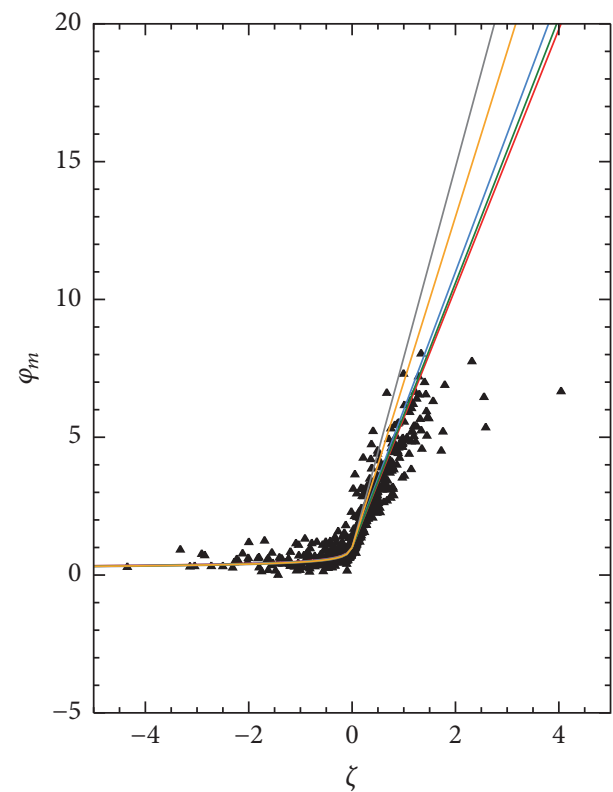

(b)

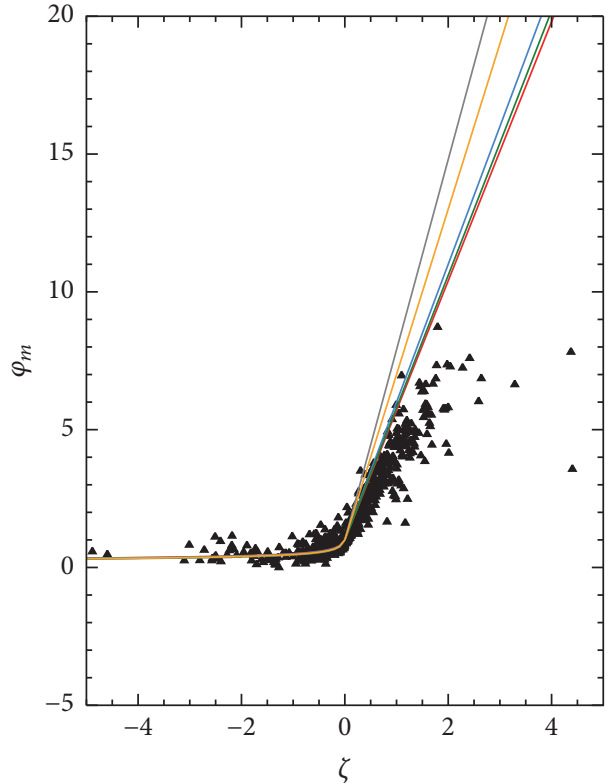

(c)

FIGURE 3: Relationship between dimensionless velocity gradient $\left(\varphi_{m}\right)$ and atmospheric stability ( $\zeta$ ) for (a) EMT 1, (b) EMT 2, and (c) EMT 3. Blue and black triangles are the records with $\tau_{\text {gap }}<1 \mathrm{~min}$ and $\tau_{\text {gap }} \geq 1 \mathrm{~min}$, respectively. Red, blue, grey, green, and yellow solid lines are the universal functions proposed by Businger et al. [21], Dyer [22], Wieringa [23], Högström [24] and Foken [25], respectively.

TABLE 3: Differences between observed values of $\varphi_{m}$ and values estimated using universal function of Businger et al. [21].

\begin{tabular}{lccccccrr}
\hline$\zeta$ & \multicolumn{4}{c}{ Unstable } & \multicolumn{3}{c}{ Stable } \\
& $-2.0--1.5$ & $-1.5--1.0$ & $-1.0--0.5$ & $-0.5-0$ & $0-0.5$ & $0.5-1.0$ & $1.0-1.5$ & $-1.18-2.0$ \\
\hline EMT 1 & 0.44 & 0.74 & 0.44 & 0.06 & 0.01 & -0.23 & -3.07 \\
EMT 2 & 0.14 & 0.00 & 0.05 & 0.00 & -0.01 & -0.48 & -1.15 \\
EMT 3 & 0.01 & -0.09 & 0.02 & 0.01 & -0.22 & -1.01 & -1.99 & -3.31 \\
\hline
\end{tabular}

Note. $\zeta$ is atmospheric stability. EMT 1, EMT 2, and EMT 3 correspond to Figures 3(a)-3(c), respectively. Positive values indicate observed values are greater than estimated ones; negative values indicate the opposite. 

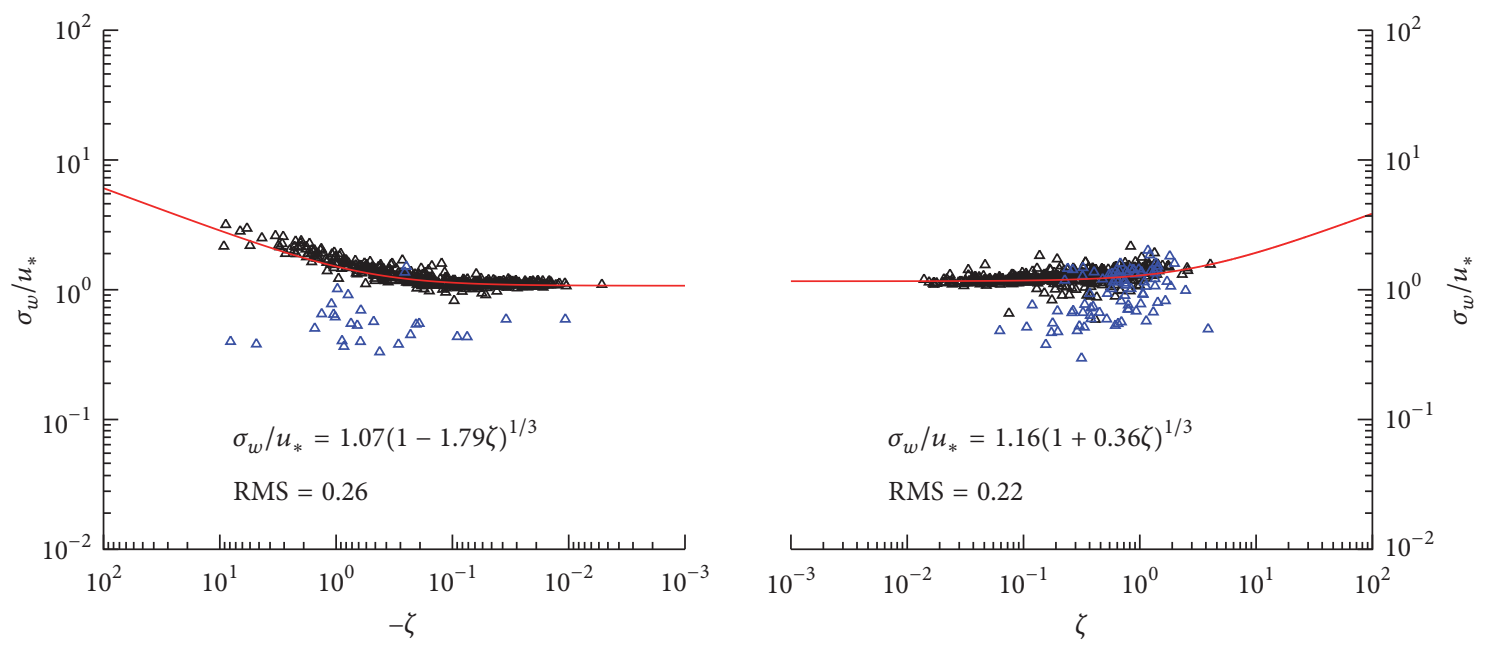

(a)
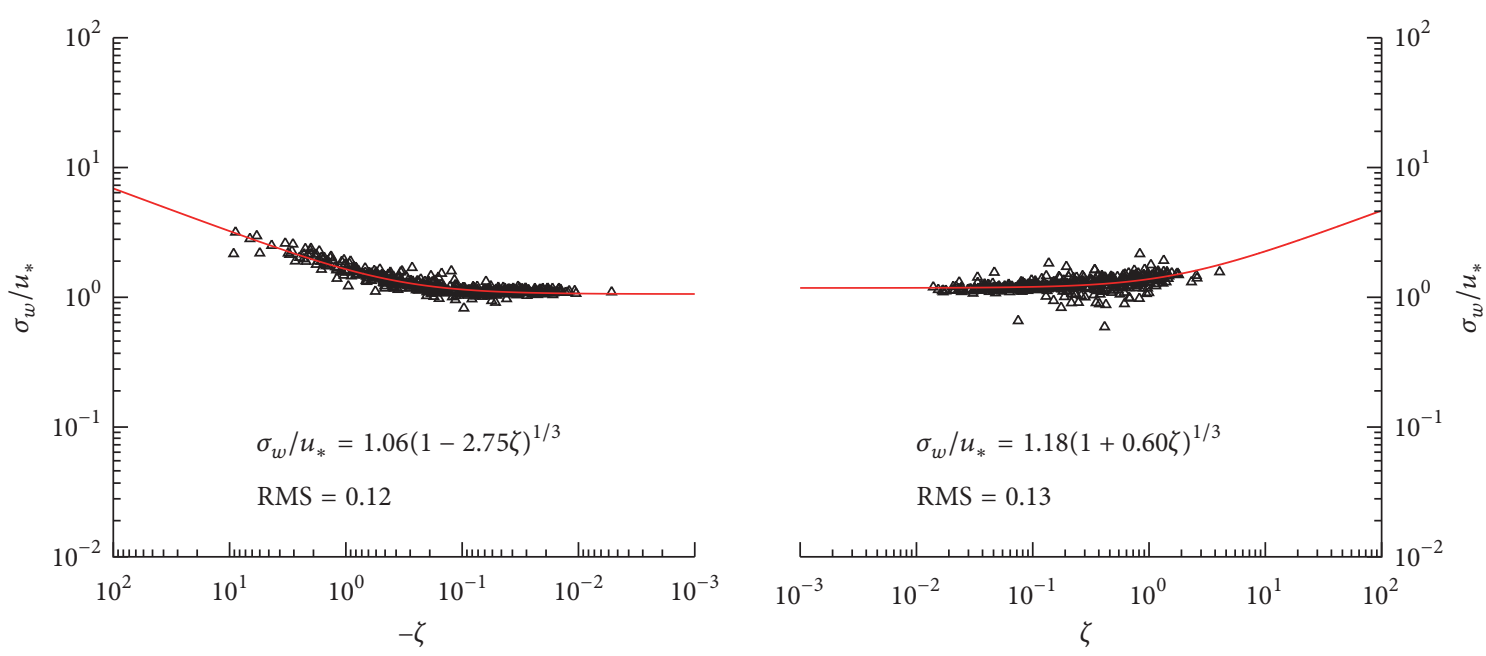

(b)
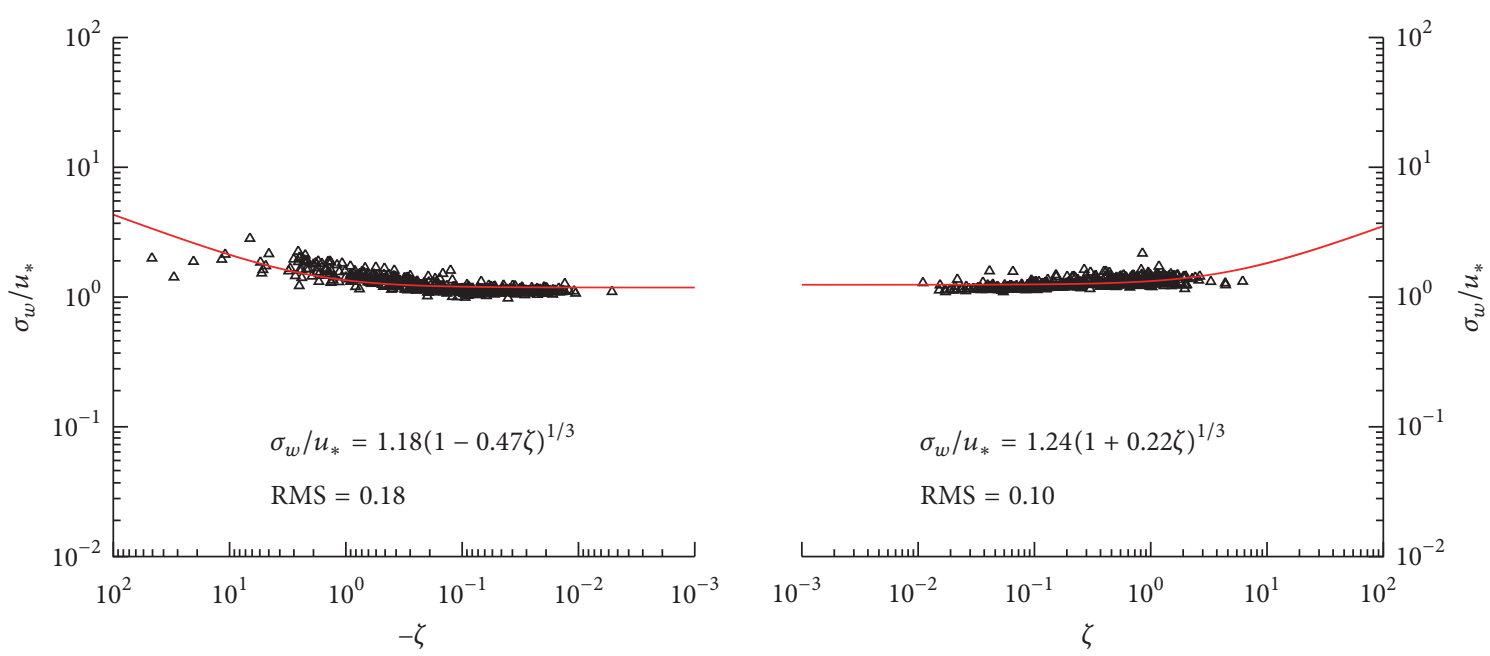

(c)

FIGURE 4: Relationship between normalized standard deviation of vertical velocity $\left(\sigma_{w} / u_{*}\right)$ and atmospheric stability $(\zeta)$ for (a) EMT 1 , (b) EMT 2, and (c) EMT 3. Blue and black triangles are records where $\tau_{\text {gap }}<1 \mathrm{~min}$ and $\tau_{\text {gap }} \geq 1 \mathrm{~min}$, respectively. Red line is the fitted curve, and RMS is the root mean square error relative to the fitted curve. 


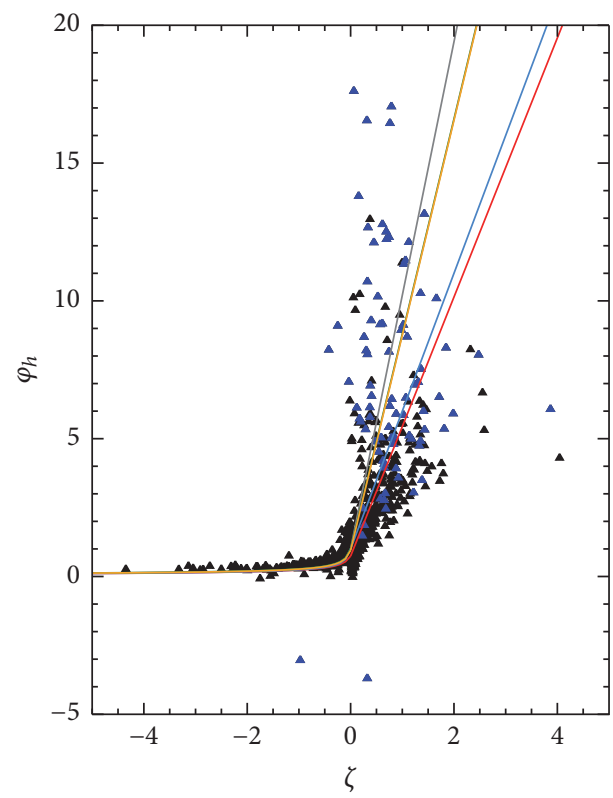

(a)

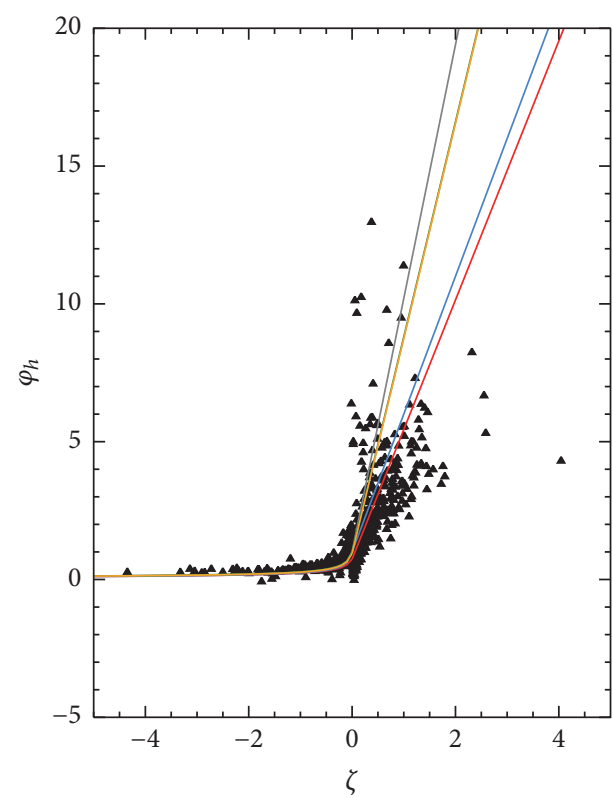

(b)

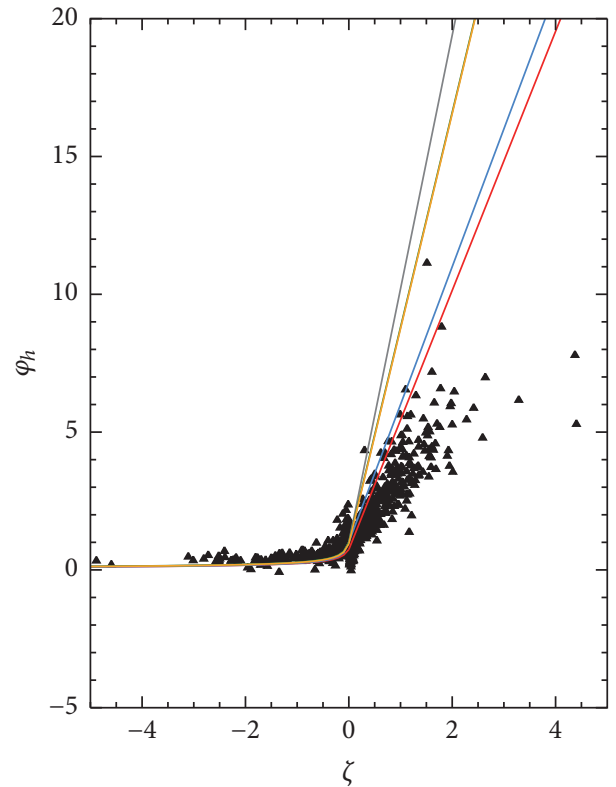

(c)

Figure 5: Same as Figure 3, but for the dimensionless temperature gradient $\left(\varphi_{h}\right)$. The universal functions proposed by Högström [24] and Foken [25] are almost the same when $\zeta>0$.

$\alpha$ is increased and $\beta$ is decreased (absolute values) in either stable or unstable conditions.

The impact of mesoscale motions on the flux-gradient and flux-variance relationship for temperature is similar to the case for wind speed. The flux-gradient relationship for temperature is shown in Figure 5. After mesoscale motions are excluded, the scatter between the dimensionless temperature gradient $\left(\varphi_{h}\right)$ and atmospheric stability $(\zeta)$ shows an evident decrease, especially in stable conditions. The observed values of $\varphi_{h}$ become smaller than the values estimated by the five universal functions in stable conditions. Among the five universal functions, the results of the universal function proposed by Businger et al. [21] are still closest to the observed results. Table 4 quantitatively compares the observed values of $\varphi_{h}$ and those estimated using the universal function of Businger et al. [21]. Table 4 shows that, after mesoscale motions are excluded by the EMT 3 method, the observed values of $\varphi_{h}$ are slightly higher than the estimated values in unstable conditions. Meanwhile, in stable conditions, the observed values of $\varphi_{h}$ become smaller than the estimated values, and the larger the $\zeta$ is, the larger the deviations will be. The flux-variance relationship for temperature is 
TABLE 4: Differences between observed values of $\varphi_{h}$ and values estimated using the universal function of Businger et al. [21].

\begin{tabular}{lccccccrr}
\hline$\zeta$ & \multicolumn{4}{c}{ Unstable } & \multicolumn{3}{c}{ Stable } \\
\hline EMT 1 & $-2.0--1.5$ & $-1.5--1.0$ & $-1.0-0.5$ & $-0.5-0$ & $0-0.5$ & $0.5-1.0$ & $1.0-1.5$ & -0.92 \\
EMT 2 & 0.06 & 0.15 & 0.10 & 0.41 & 0.46 & 0.43 & -3.30 \\
EMT 3 & 0.06 & 0.15 & 0.18 & 0.35 & 0.11 & -0.60 & -2.02 \\
\hline
\end{tabular}

Note. $\zeta$ is atmospheric stability. EMT 1, EMT 2, and EMT 3 correspond to Figures 5(a)-5(c), respectively. Positive values indicate observed values are greater than estimated ones; negative values indicate the opposite.

shown in Figure 6. After mesoscale motions are excluded, the scatter between the normalized standard deviation of temperature $\left(\sigma_{T} / T_{*}\right)$ and atmospheric stability $(\zeta)$ clearly decreases, especially in stable conditions. The fit coefficients between $\sigma_{T} / T_{*}$ and $\zeta$ obviously decrease. Moreover, the relationship between $\sigma_{T} / T_{*}$ and $\zeta$ clearly deviates from the $-1 / 3$ power law after mesoscale motions are excluded.

\subsection{Impact of Mesoscale Motion on Surface Energy Balance.} After mesoscale motions are removed, the decreased scatter in similarity relations reflects that the turbulent fluxes are significantly improved and the research results can more accurately describe the actual characteristics of atmospheric turbulence. However, the effect of the improved turbulent fluxes on the surface energy transfer needs to be further studied. Therefore, the effect of mesoscale motions on surface energy balance is analyzed in this section. The energy balance closure problem is related to multiple factors. To investigate the effect of mesoscale motions on surface energy balance closure, it is necessary to exclude other influencing factors first. The main components of the energy balance closure problem can be summarized as follows: heterogeneous surfaces [39], canopy heat storage [7], low-frequency loss [35], uncertainty in determining surface soil heat flux [40], and instrument footprint-scale mismatch [8]. The effects of a heterogeneous surface, canopy heat storage, low-frequency loss, and instrument footprint-scale mismatch are negligible because the data used in this study were observed on a homogeneous bare soil surface, and several data processing methods (see Site Description and Instrumentation section) are used to guarantee the quality of turbulence data. However, the uncertainty in determining the surface soil heat flux is relatively large. Thus, three commonly used methods (PlateCal method [41], TDEC method [42], and Harmonic method [43]) were adopted to calculate the surface soil heat flux, based on which we analyze the effect of mesoscale motions on the surface energy balance and examine whether there are essential differences among the results when $G_{0}$ is calculated using those three methods.

The research of surface energy balance usually shows that the available energy is greater than the turbulent flux $\left(0<\mathrm{EBR}_{h}<1\right)$. However, some researches [44] also noted that there are some outliers with $\mathrm{EBR}_{h}>1$ or $\mathrm{EBR}_{h}<0$. When the observation data are used to validate and improve the numerical models, these energy balance closure outliers with instant scale will exert a serious impact on the model verification. Mesoscale motions result in much uncertainty in the observed turbulent fluxes, which is likely to increase the number of $\mathrm{EBR}_{h}$ outliers. Figure 7 shows the daily change in the number of $\mathrm{EBR}_{h}$ outliers before and after the exclusion of mesoscale motions. Figure 7 indicates that the effect of mesoscale motions on $\mathrm{EBR}_{h}$ outliers occurs mainly at night, and no matter which method is used to calculate $G_{0}$, the number of $\mathrm{EBR}_{h}$ outliers at night is significantly reduced after mesoscale motions are removed. The exclusion of mesoscale motions by the EMT 2 method decreases the number of $\mathrm{EBR}_{h}$ outliers by $47.2 \%$, $40.2 \%$, and $22.4 \%$ during the nighttime, corresponding to the use of the PlateCal, TDEC, and Harmonic methods, respectively, in calculating $G_{0}$. After mesoscale motions are further excluded by the EMT 3 method, the number of $\mathrm{EBR}_{h}$ outliers during the night decreases by $52.0 \%, 46.7 \%$, and $28.3 \%$, respectively, corresponding to the three methods of calculating $G_{0}$. After mesoscale motions are excluded, the total number of $\mathrm{EBR}_{h}$ outliers during the night decreases by $68.1 \%, 62.2 \%$, and $33.9 \%$, respectively, corresponding to the above three methods for calculating $G_{0}$, which indicates that mesoscale motions are an important reason for $\mathrm{EBR}_{h}$ outliers.

To analyze the effect of mesoscale motions on EBR, the daily change in EBR before and after the exclusion of mesoscale motions is shown in Figure 8. The removal of mesoscale motions exerts little effect in the daytime but has obvious effects on EBR during the nighttime. There are significant differences in EBR when $G_{0}$ is calculated by different methods. However, no matter which method is used to calculate $G_{0}$, EBR during the nighttime is improved after mesoscale motions are excluded. In the EMT 1, EBR during the night is $55.0 \%, 53.3 \%$, and $60.9 \%$, corresponding to the use of the PlateCal, TDEC, and Harmonic methods, respectively, in calculating $G_{0}$. After mesoscale motions are excluded by the EMT 2 method, EBR increases dramatically at all hours of the night and increases to $60.5 \%, 58.8 \%$, and $65.3 \%$, corresponding to the use of the three methods in calculating $G_{0}$, respectively. When mesoscale motions are further excluded by the EMT 3 method, EBR during the night further increases to $60.8 \%, 59.1 \%$, and $65.7 \%$ corresponding to the above three $G_{0}$ calculation methods, respectively, and its variation becomes smoother. In other words, the exclusion of mesoscale motions increases the EBR during the night by $5.8 \%, 5.8 \%$, and $4.8 \%$ corresponding to the above three $G_{0}$ calculation methods, respectively. These results suggest that mesoscale motions have a significant influence on EBR and perhaps reduce the surface energy balance closure during the night.

Recent research has shown that surface energy balance closure is determined by the turbulence intensity [34], and 

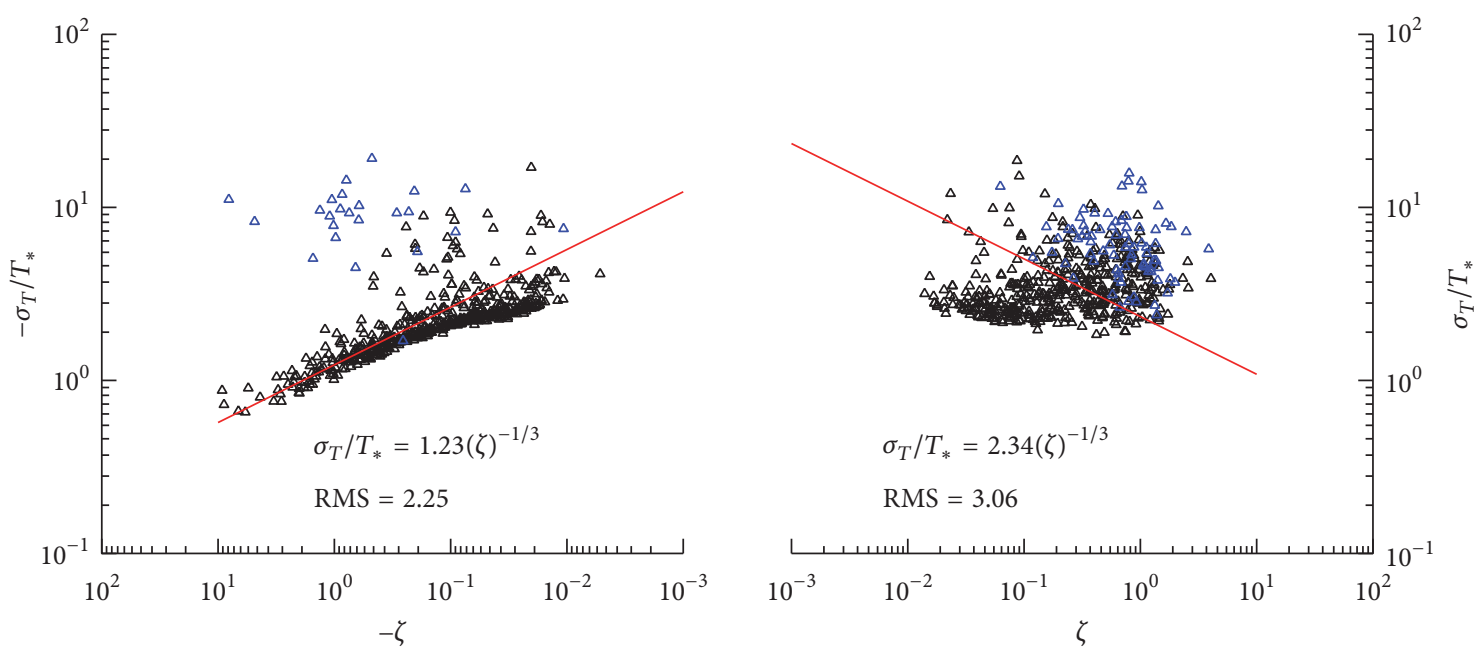

(a)
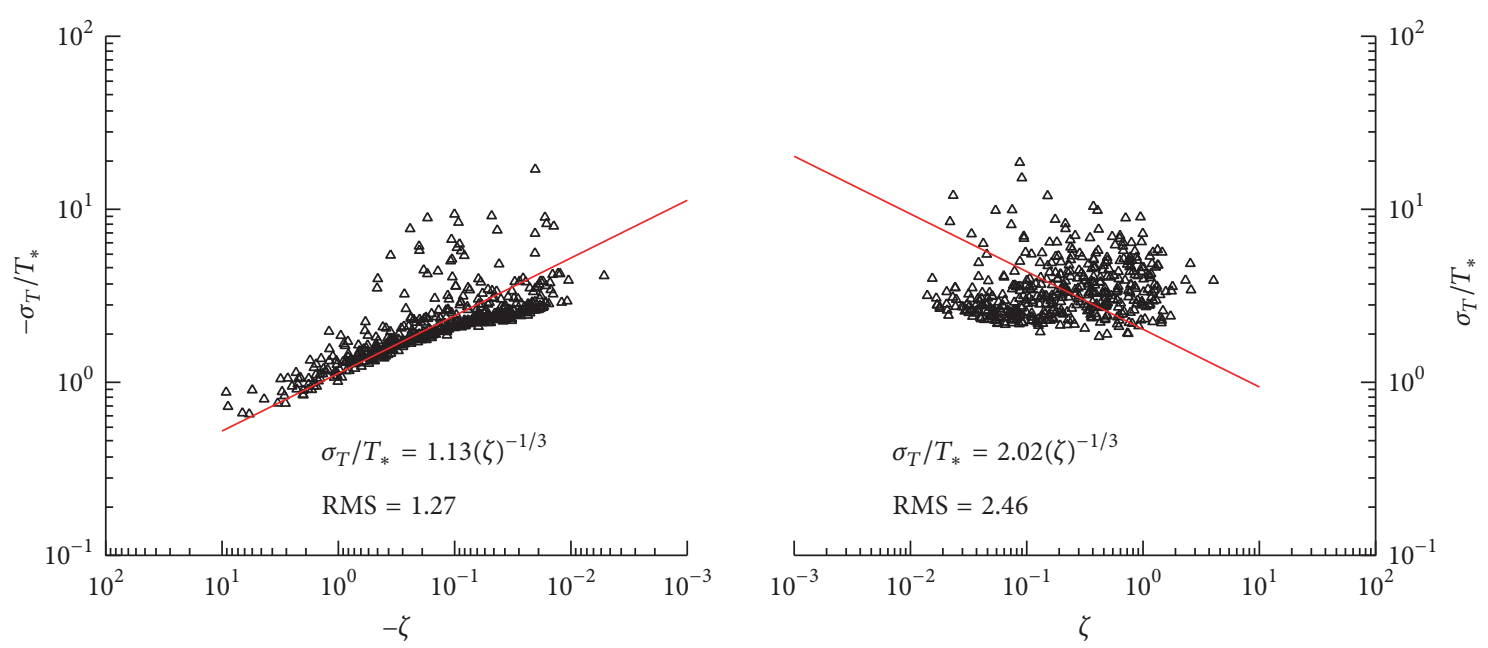

(b)
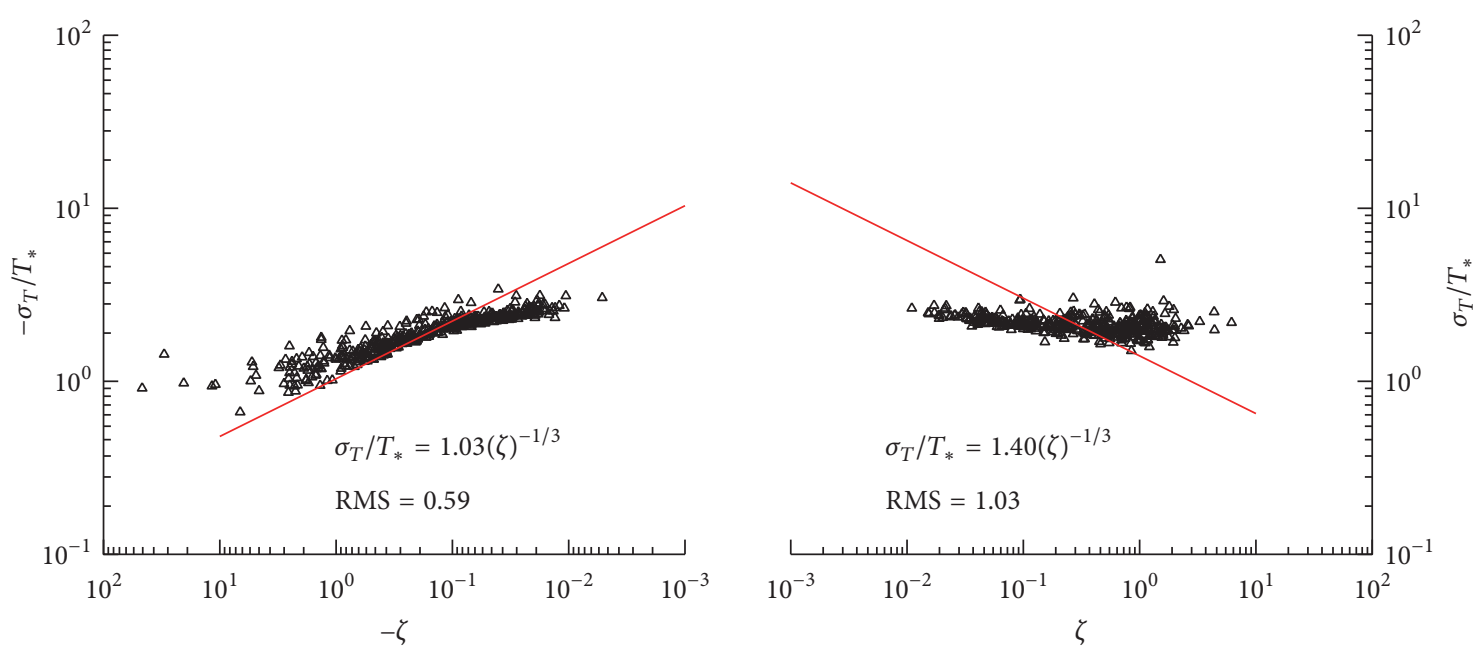

(c)

FIGURE 6: Same as Figure 4, but for normalized standard deviation of temperature $\left(\sigma_{T} / T_{*}\right)$. 

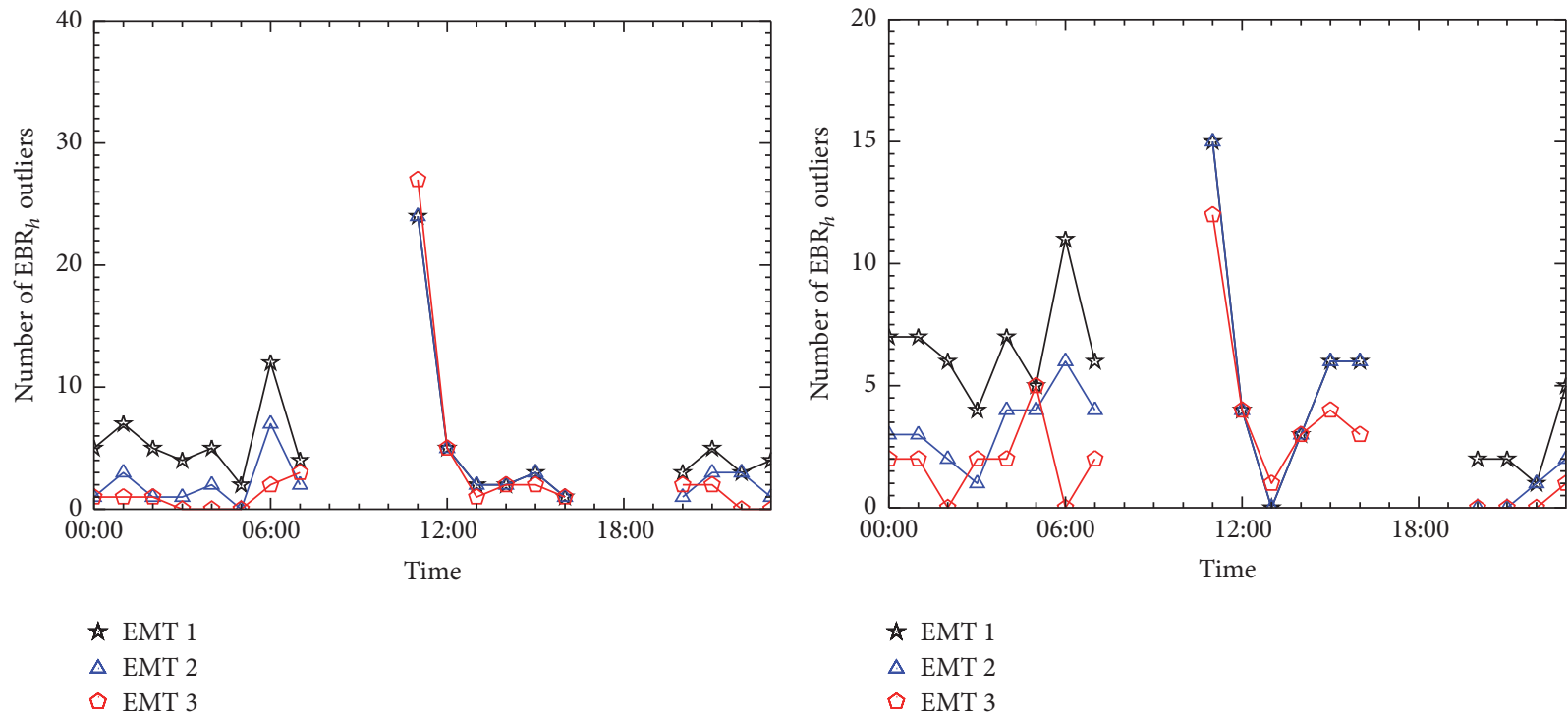

4. EMT 1

$\triangle$ EMT 2

$\checkmark$ EMT 3

(a)

(b)

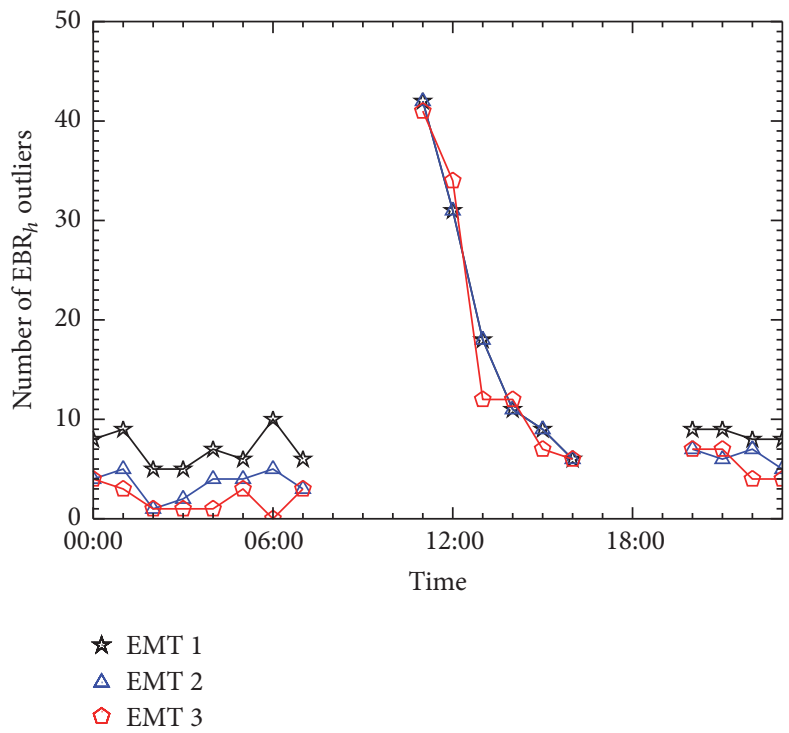

(c)

FIGURE 7: Daily change in number of energy balance ratio $\left(\mathrm{EBR}_{h}\right)$ outliers. $\mathrm{EBR}_{h}$ outliers are defined as the records with $\mathrm{EBR}_{h}<0$ or $\mathrm{EBR}_{h}>1$. (a), (b), and (c) are, respectively, cases where $G_{0}$ was calculated using the PlateCal, TDEC, and Harmonic methods.

the former increases with the strengthening of the latter. When turbulent mixing is weak, the surface energy balance closure is usually low and the mesoscale motions are active, for which reason the effect of mesoscale motions is likely the reason for poor energy balance closure. Since mesoscale motions impact energy balance closure mainly at night, the change in EBR with the relative vertical turbulent intensity $\left(\mathrm{RI}_{w}\right)$ during the night is analyzed using the method of Zuo et al. [34]. Figure 9 shows that the exclusion of mesoscale motions increases EBR when turbulent mixing is weak, which is independent of the $G_{0}$ calculation method. However, when turbulent mixing is weak, EBR is still generally low, even after mesoscale motions are excluded. Considering that mesoscale motions can also contribute to the energy transport $[16,45]$, the energy exchange may occur mainly by mesoscale motions when turbulent mixing is weak, and the contribution of turbulence is small. If the energy transport by mesoscale motions can be accurately measured, the energy balance closure should be further improved when turbulent mixing is weak.

\section{Conclusions and Discussions}

Atmospheric motions have multiscale characteristics, and although these scales are distinguishable from one another, they interact and are closely correlated. The relationship between turbulence and mesoscale motions also follows this rule. With the help of the spectral gap in the atmospheric 

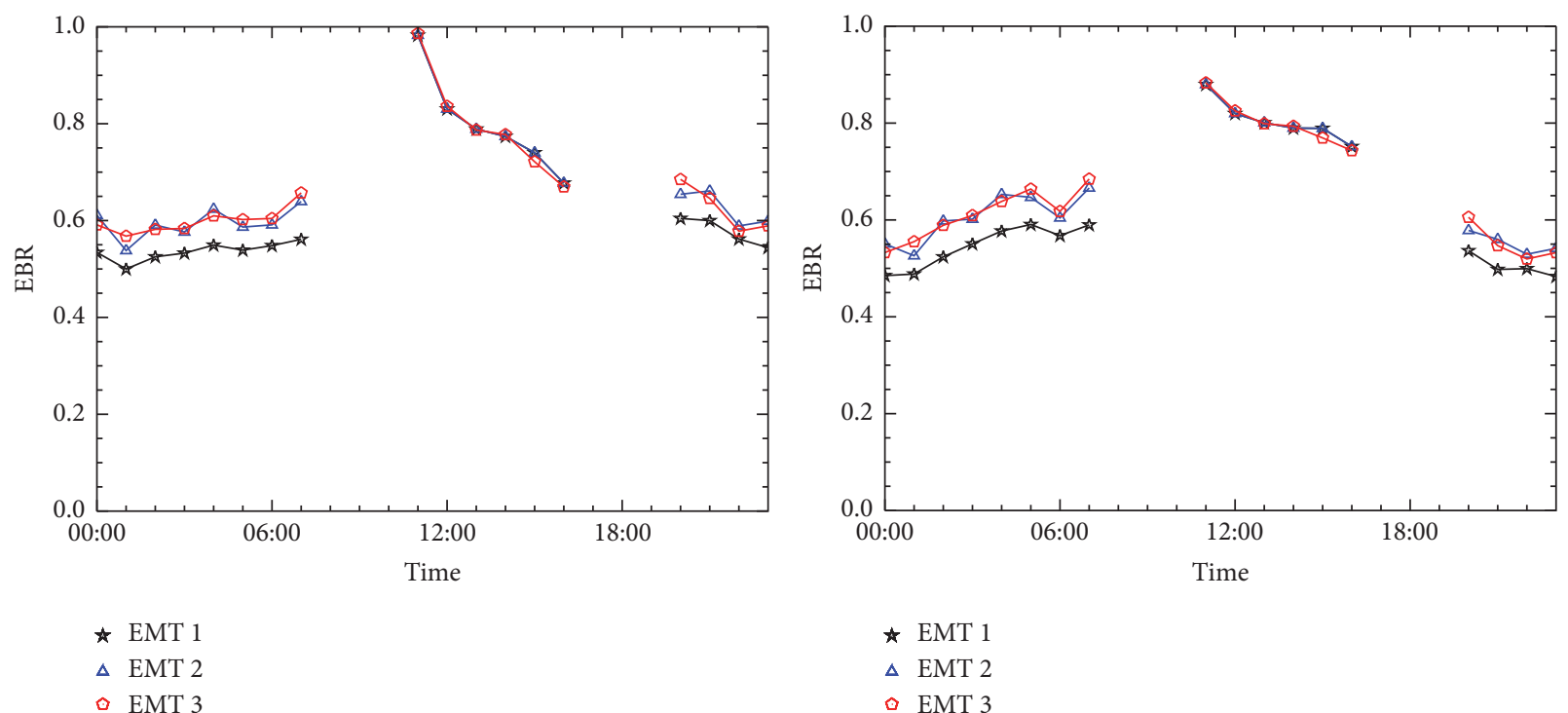

(a)

(b)

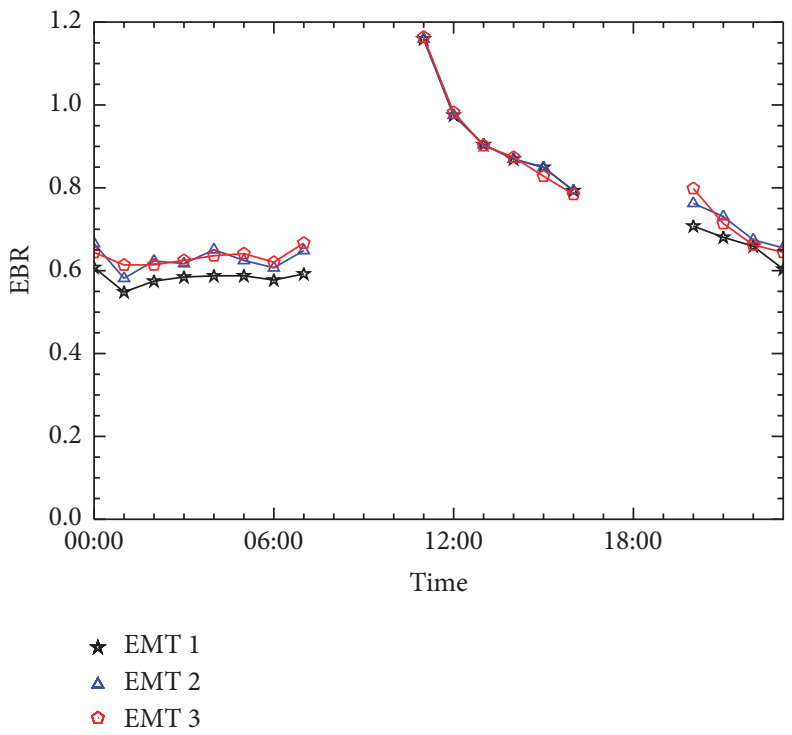

(c)

FIGURE 8: Daily change in energy balance ratio (EBR). (a), (b), and (c) are, respectively, cases where $G_{0}$ was calculated using the PlateCal, TDEC, and Harmonic methods.

motion spectrum, turbulence can be separated from larger scale motions, and the atmospheric turbulence is studied independently. However, if the turbulence is not strictly extracted according to the spectral gap, the research results may be affected by the mesoscale motions and cannot reflect the actual characteristics of the turbulence. The effect of mesoscale motions can be reflected in the applicability of MOST and the surface energy balance closure and adds much difficulty to the study of these two issues. In much of the relevant research, the disturbance of heterogeneous surface and vegetation-covered surface also adds much uncertainty to these two fields of study. Therefore, in this study we conducted an experiment on a homogeneous bare soil surface and investigated the impact of mesoscale motions on MOST and the surface energy balance.

Our study indicates that mesoscale motions do not follow MOST, so the application of MOST is limited once turbulent fluxes are contaminated by mesoscale motions; this is reflected in the scatter of the similarity relations and the applicability of universal functions. On the one hand, MOST mainly depicts the key feature of turbulence in the boundary layer, but the contamination of mesoscale motions results in scattered similarity relations. The similarity relations become scattered in both stable and unstable conditions, but especially in stable conditions. On the other hand, the universal functions of similarity theory successfully 


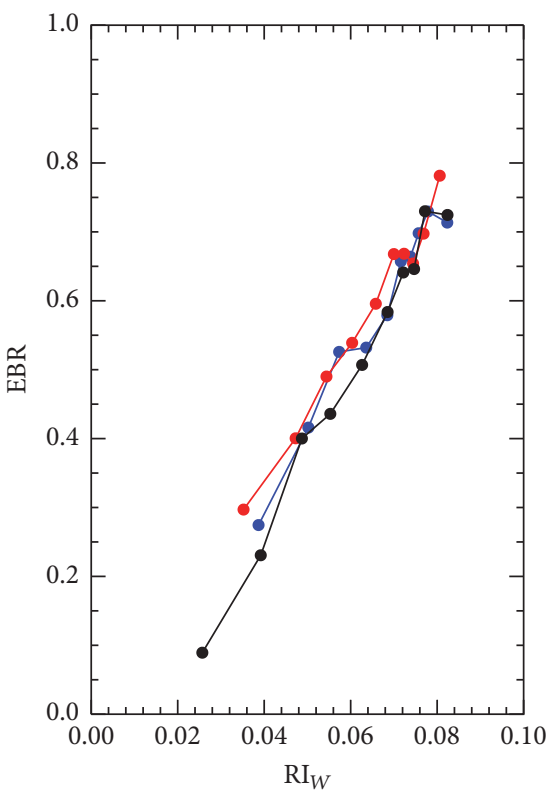

- EMT 1

- EMT 2

- EMT 3

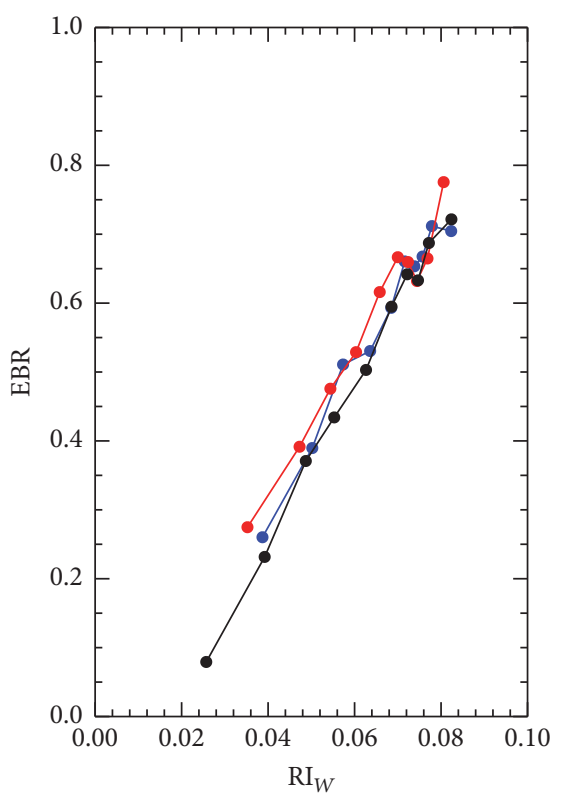

- EMT 1

- EMT 2

- EMT 3

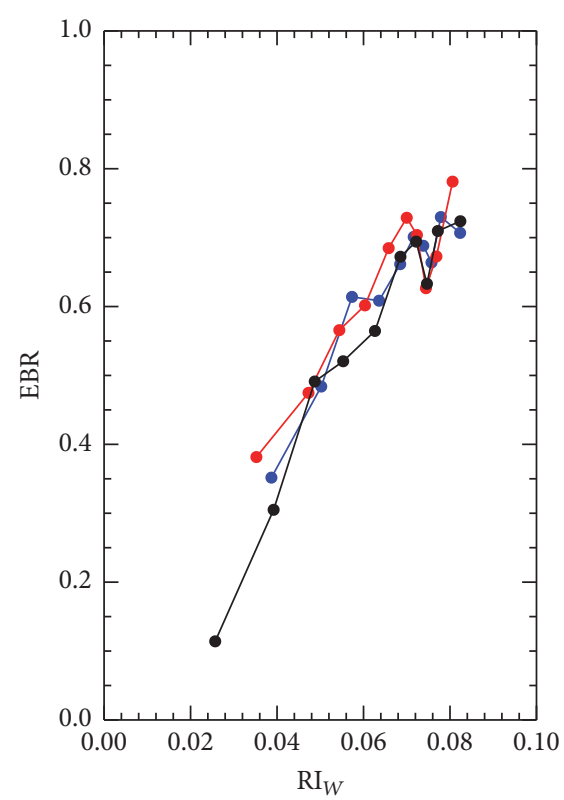

- EMT 1

- EMT 2

- EMT 3

(a)

(c)

FIGURE 9: Relationship between energy balance ratio (EBR) and relative vertical turbulent intensity $\left(\mathrm{RI}_{w}\right)$. (a), (b), and (c) are, respectively, cases where $G_{0}$ was calculated using the PlateCal, TDEC, and Harmonic methods.

describe the relationship between normalized physical variables and the atmospheric stability in the boundary layer, but mesoscale motions cause the turbulent characteristic values to deviate from the estimated values of MOST, which limits the applicability of the original universal functions to a certain extent. This is revealed by the fact that the removal of mesoscale motions makes the observed values of the dimensionless velocity gradient $\left(\varphi_{m}\right)$ and dimensionless temperature gradient $\left(\varphi_{h}\right)$ in stable conditions less than the estimated values of all five types of universal functions. Furthermore, the more stable the atmosphere is, the larger the deviations will be. Meanwhile, the exclusion of mesoscale motions also causes obvious changes to the fit coefficients of the flux-variance relationship and makes flux-variance relationship for temperature clearly deviate from the $-1 / 3$ power law.

Mesoscale motions also affect the energy balance closure. Mesoscale motions introduce great uncertainty into the turbulent fluxes, which yields quite a number of energy balance closure outliers and decreases the energy balance ratio. The influence of mesoscale motions on the surface energy balance exists in both daytime and nighttime and is especially obvious during the night and weak turbulent mixing periods. During the night, the number of energy balance closure outliers drops dramatically, and the energy balance ratio increases evidently with the exclusion of mesoscale motions. This suggests that mesoscale motion is an important reason for the poor energy balance closure at night. However, when turbulent mixing is weak, the energy balance closure is still low, even after mesoscale motions are excluded, which indicates that the energy transport is not completely undertaken by turbulence at this time, and mesoscale motions may also contribute to the energy transport.

Excluding mesoscale motions can effectively reduce the uncertainty in the study of MOST and surface energy balance closure, but some new problems also emerge. These new problems mainly include the enlargement of the deviation of the values estimated by the MOST universal functions from the observations and the deviation of the flux-variance relationship for temperature from the $-1 / 3$ power law. More high-quality observation data are needed to confirm the results revealed in the present study and to improve MOST. In the analysis of the surface energy balance, mesoscale motions are excluded, while previous studies have revealed that mesoscale motions can actually transport energy and matter near the surface $[16,45,46]$. However, the spatial and temporal scales of mesoscale fluxes are very large, and the intensity and direction of vertical transport are inhomogeneous in the horizontal direction, for which reason the energy flux transported by mesoscale motions is difficult to detect accurately at a single tower site $[16,47]$. Therefore, the energy balance closure is often better when turbulent mixing is strong than when turbulent mixing is weak. In the future, it is necessary to observe the mesoscale fluxes on a larger spatial scale by observation means such as radar, aircraft, and multitowers. If the energy transported by mesoscale motions can be accurately measured, the energy balance closure during the night and weak turbulent mixing periods should 
be better than the current study, where the disturbances from mesoscale motions are removed.

\section{Conflicts of Interest}

The authors declare that there are no conflicts of interest regarding the publication of this paper.

\section{Acknowledgments}

This work is supported by the National Basic Research Program of China (2012CB956202), National Natural Science Foundation of China (41275019, 41475009), and Fundamental Research Funds for the Central Universities (lzujbky-2016196).

\section{References}

[1] A. S. Monin and A. M. F. Obukhov, "Basic laws of turbulent mixing in the surface layer of the atmosphere," Trudy Geofizicheskogo Instituta, Akademiya Nauk SSSR, vol. 24, no. 151, pp. 163187, 1954.

[2] T. Foken, "50 years of the Monin-Obukhov similarity theory," Boundary Layer Meteorology, vol. 119, no. 3, pp. 431-447, 2006.

[3] P. Kumar and M. Sharan, "An analysis for the applicability of Monin-Obukhov similarity theory in stable conditions," Journal of the Atmospheric Sciences, vol. 69, no. 6, pp. 1910-1915, 2012.

[4] J. Liang, L. Zhang, Y. Wang et al., "Turbulence regimes and the validity of similarity theory in the stable boundary layer over complex terrain of the Loess Plateau, China," Journal of Geophysical Research: Atmospheres, vol. 119, no. 10, pp. 60096021, 2014.

[5] J. Zou, G. Liu, J. Sun, H. Zhang, and R. Yuan, "The momentum flux-gradient relations derived from field measurements in the urban roughness sublayer in three cities in China," Journal of Geophysical Research: Atmospheres, vol. 120, no. 20, pp. 1079710809, 2015.

[6] K. Wilson, A. Goldstein, E. Falge et al., "Energy balance closure at FLUXNET sites," Agricultural and Forest Meteorology, vol. 113, no. 1-4, pp. 223-243, 2002.

[7] S. P. Oncley, T. Foken, R. Vogt et al., "The energy balance experiment EBEX-2000. Part I: Overview and energy balance," Boundary Layer Meteorology, vol. 123, no. 1, pp. 1-28, 2007.

[8] T. Foken, "The energy balance closure problem: an overview," Ecological Applications, vol. 18, no. 6, pp. 1351-1367, 2008.

[9] R. Leuning, E. van Gorsel, W. J. Massman, and P. R. Isaac, "Reflections on the surface energy imbalance problem," Agricultural and Forest Meteorology, vol. 156, pp. 65-74, 2012.

[10] Q. Zhang, H. Y. Li, and J. H. Zhao, "Modification of the land surface energy balance relationship by introducing vertical sensible heat advection and soil heat storage over the Loess Plateau," Science China Earth Sciences, vol. 55, no. 4, pp. 580589, 2012.

[11] K.-J. Ha, Y.-K. Hyun, H.-M. Oh, K.-E. Kim, and L. Mahrt, "Evaluation of boundary layer similarity theory for stable conditions in CASES-99," Monthly Weather Review, vol. 135, no. 10, pp. 3474-3483, 2007.

[12] L. Mahrt, "The influence of nonstationarity on the turbulent flux-gradient relationship for stable stratification," Boundary Layer Meteorology, vol. 125, no. 2, pp. 245-264, 2007.
[13] L. Mahrt, "Weak-wind mesoscale meandering in the nocturnal boundary layer," Environmental Fluid Mechanics, vol. 7, no. 4, pp. 331-347, 2007.

[14] L. Mahrt, C. K. Thomas, and J. H. Prueger, "Space-time structure of mesoscale motions in the stable boundary layer," Quarterly Journal of the Royal Meteorological Society, vol. 135, no. 638, pp. 67-75, 2009.

[15] D. Vickers and L. Mahrt, "The cospectral gap and turbulent flux calculations," Journal of Atmospheric and Oceanic Technology, vol. 20, no. 5, pp. 660-672, 2003.

[16] L. Mahrt, "Computing turbulent fluxes near the surface: Needed improvements," Agricultural and Forest Meteorology, vol. 150, no. 4, pp. 501-509, 2010.

[17] Z. Sorbjan and A. A. Grachev, "An evaluation of the fluxgradient relationship in the stable boundary layer," Boundary Layer Meteorology, vol. 135, no. 3, pp. 385-405, 2010.

[18] K. Babić, M. W. Rotach, and Z. B. Klaić, "Evaluation of local similarity theory in the wintertime nocturnal boundary layer over heterogeneous surface," Agricultural and Forest Meteorology, vol. 228-229, pp. 164-179, 2016.

[19] D. Vickers and L. Mahrt, "A solution for flux contamination by mesoscale motions with very weak turbulence," Boundary Layer Meteorology, vol. 118, no. 3, pp. 431-447, 2006.

[20] H. Zuo, B. Chen, S. Wang et al., "Observational study on complementary relationship between pan evaporation and actual evapotranspiration and its variation with pan type," Agricultural and Forest Meteorology, vol. 222, pp. 1-9, 2016.

[21] J. A. Businger, J. C. Wyngaard, Y. Izumi, and E. F. Bradley, "Fluxprofile relationships in the atmospheric surface layer," Journal of the Atmospheric Sciences, vol. 28, no. 2, pp. 181-189, 1971.

[22] A. J. Dyer, "A review of flux-profile relationships," Boundary Layer Meteorology, vol. 7, no. 3, pp. 363-372, 1974.

[23] J. Wieringa, "A revaluation of the Kansas mast influence on measurements of stress and cup anemometer overspeeding," Boundary Layer Meteorology, vol. 18, no. 4, pp. 411-430, 1980.

[24] U. Högström, "Non-dimensional wind and temperature profiles in the atmospheric surface layer: a re-evaluation," Boundary Layer Meteorology, vol. 42, no. 1-2, pp. 55-78, 1988.

[25] T. Foken, Micrometeorology, Springer Science \& Business Media, Berlin, Germany, 2008.

[26] R. Clement, "Edire software," http://www.geos.ed.ac.uk/homes/ jbm/micromet/EdiRe/, University of Edinburgh, 2012.

[27] D. Vickers and L. Mahrt, "Quality control and flux sampling problems for tower and aircraft data," Journal of Atmospheric and Oceanic Technology, vol. 14, no. 3, pp. 512-526, 1997.

[28] J. M. Wilczak, S. P. Oncley, and S. A. Stage, "Sonic anemometer tilt correction algorithms," Boundary Layer Meteorology, vol. 99, no. 1, pp. 127-150, 2001.

[29] J. C. Kaimal and J. E. Gaynor, "Another look at sonic thermometry," Boundary Layer Meteorology, vol. 56, no. 4, pp. 401-410, 1991.

[30] W. J. Massman, "A simple method for estimating frequency response corrections for eddy covariance systems," Agricultural and Forest Meteorology, vol. 104, no. 3, pp. 185-198, 2000.

[31] E. K. Webb, G. I. Pearman, and R. Leuning, "Correction of flux measurements for density effects due to heat and water vapour transfer," Quarterly Journal of the Royal Meteorological Society, vol. 106, no. 447, pp. 85-100, 1980.

[32] R. Kormann and F. X. Meixner, "An analytical footprint model for non-neutral stratification," Boundary Layer Meteorology, vol. 99, no. 2, pp. 207-224, 2001. 
[33] N. Kljun, P. Calanca, M. W. Rotach, and H. P. Schmid, "A simple parameterisation for flux footprint predictions," Boundary Layer Meteorology, vol. 112, no. 3, pp. 503-523, 2004.

[34] H. Zuo, X. Xiao, Q. Yang, L. Dong, J. Chen, and S. Wang, "On the atmospheric movement and the imbalance of observed and calculated energy in the surface layer," Science China Earth Sciences, vol. 55, no. 9, pp. 1518-1532, 2012.

[35] T. Foken, F. Wimmer, M. Mauder, C. Thomas, and C. Liebethal, "Some aspects of the energy balance closure problem," Atmospheric Chemistry and Physics, vol. 6, no. 12, pp. 4395-4402, 2006.

[36] H. A. Panofsky, H. Tennekes, D. H. Lenschow, and J. C. Wyngaard, "The characteristics of turbulent velocity components in the surface layer under convective conditions," Boundary Layer Meteorology, vol. 11, no. 3, pp. 355-361, 1977.

[37] M. Roth, "Turbulent transfer relationships over an urban surface. II: Integral statistics," Quarterly Journal of the Royal Meteorological Society, vol. 119, no. 513, pp. 1105-1120, 1993.

[38] C. R. Lloyd, A. D. Culf, A. J. Dolman, and J. H. C. Gash, "Estimates of sensible heat flux from observations of temperature fluctuations," Boundary Layer Meteorology, vol. 57, no. 4, pp. 311322, 1991.

[39] P. C. Stoy, M. Mauder, T. Foken et al., "A data-driven analysis of energy balance closure across FLUXNET research sites: The role of landscape scale heterogeneity," Agricultural and Forest Meteorology, vol. 171-172, pp. 137-152, 2013.

[40] E. S. Russell, H. Liu, Z. Gao, D. Finn, and B. Lamb, "Impacts of soil heat flux calculation methods on the surface energy balance closure," Agricultural and Forest Meteorology, vol. 214-215, pp. 189-200, 2015.

[41] C. Liebethal, B. Huwe, and T. Foken, "Sensitivity analysis for two ground heat flux calculation approaches," Agricultural and Forest Meteorology, vol. 132, no. 3-4, pp. 253-262, 2005.

[42] K. Yang and J. M. Wang, "A temperature prediction-correction method for estimating surface soil heat flux from soil temperature and moisture data," Science China Earth Sciences, vol. 51, no. 5, pp. 721-729, 2008.

[43] B. G. Heusinkveld, A. F. G. Jacobs, A. A. M. Holtslag, and S. M. Berkowicz, "Surface energy balance closure in an arid region: Role of soil heat flux," Agricultural and Forest Meteorology, vol. 122, no. 1-2, pp. 21-37, 2004.

[44] J. Guo, L. Bian, and Y. Dai, "Multiple time scale evaluation of the energy balance during the maize growing season, and a new reason for energy imbalance," Science China Earth Sciences, vol. 52, no. 1, pp. 108-117, 2009.

[45] O. C. Acevedo and L. Mahrt, "Systematic vertical variation of mesoscale fluxes in the nocturnal boundary layer," Boundary Layer Meteorology, vol. 135, no. 1, pp. 19-30, 2010.

[46] F. Eder, M. Schmidt, T. Damian, K. Träumner, and M. Mauder, "Mesoscale eddies affect near-surface turbulent exchange: Evidence from lidar and tower measurements," Journal of Applied Meteorology and Climatology, vol. 54, no. 1, pp. 189-206, 2015.

[47] M. Aubinet, C. Feigenwinter, B. Heinesch et al., "Direct advection measurements do not help to solve the night-time CO2 closure problem: Evidence from three different forests," Agricultural and Forest Meteorology, vol. 150, no. 5, pp. 655-664, 2010. 

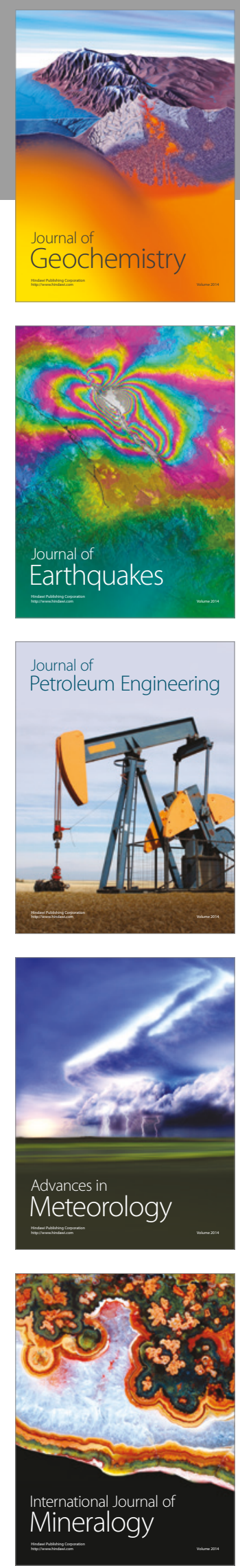
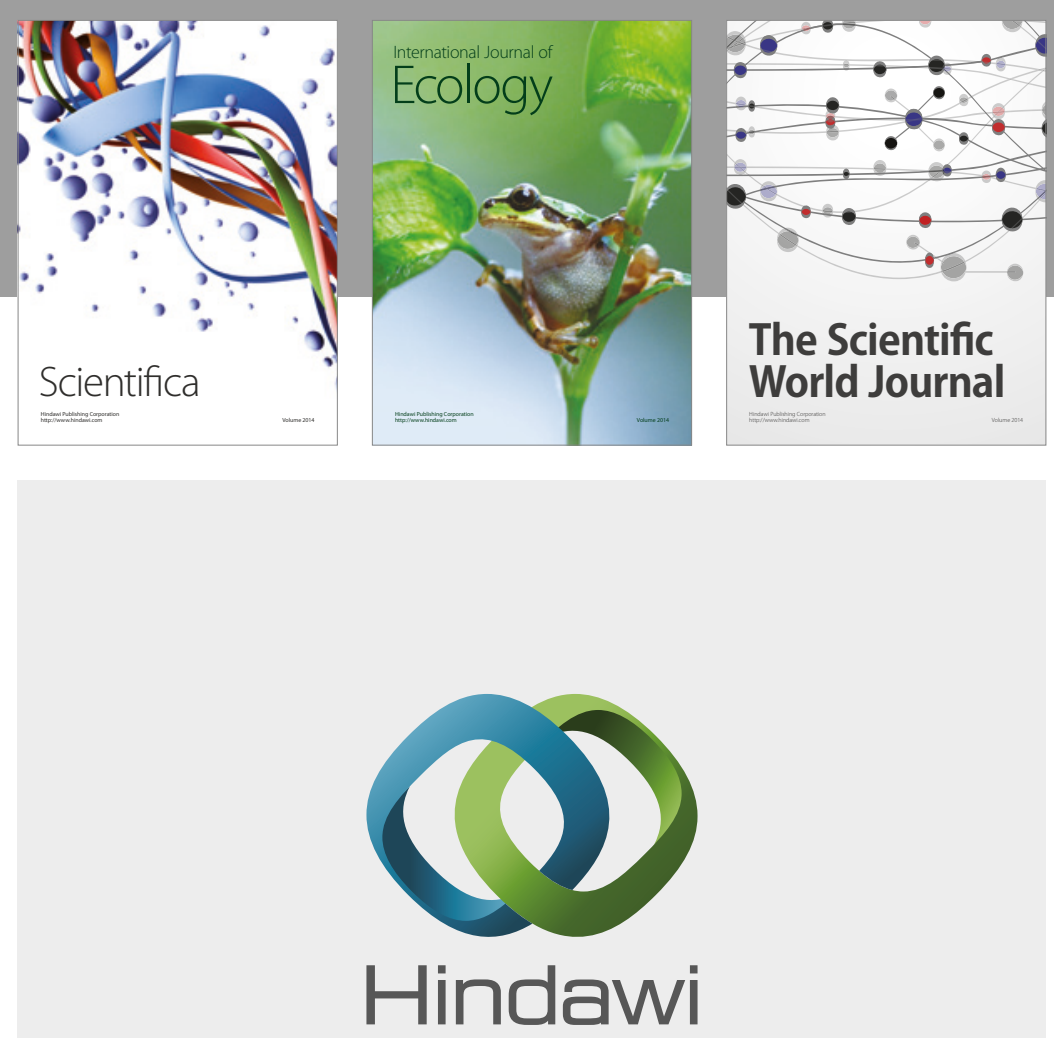

Submit your manuscripts at

https://www.hindawi.com
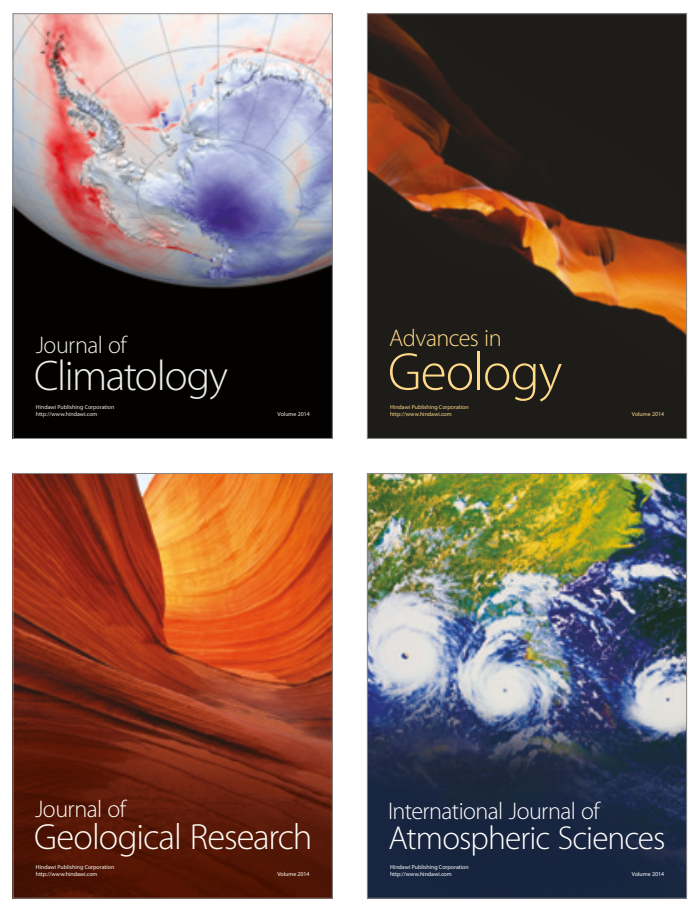

The Scientific

World Journal
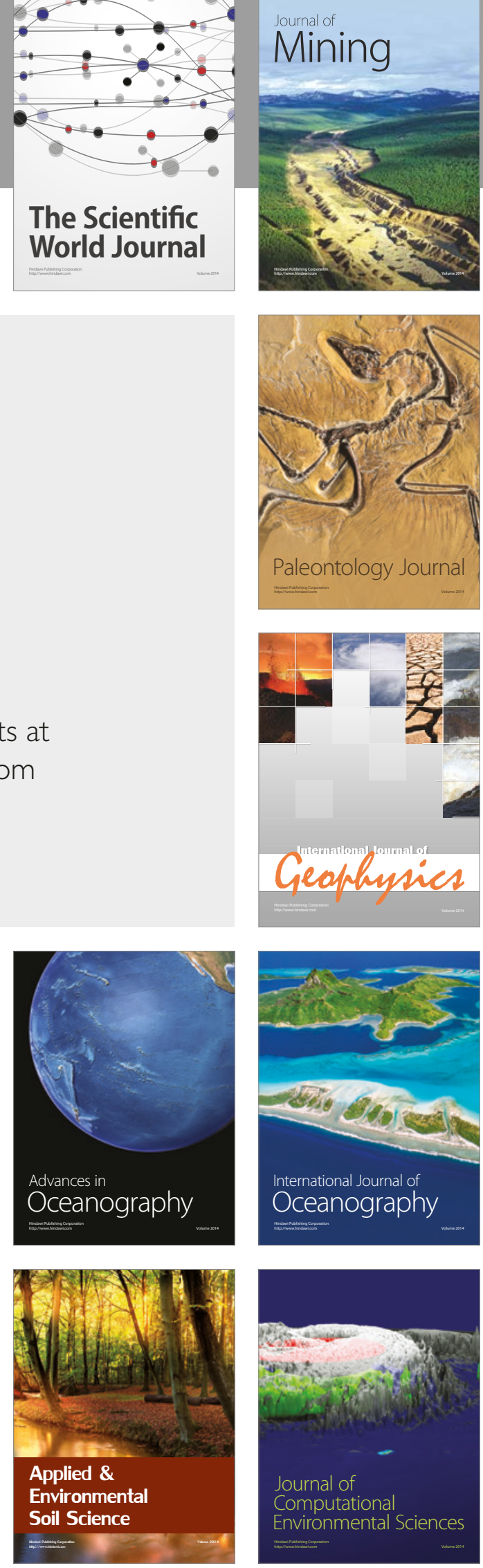